\title{
Present Simulation and Future Typhoon Activity Projection over Western North Pacific and Taiwan/East Coast of China in 20-km HiRAM Climate Model
}

\author{
Chih-Hua Tsou ${ }^{1, *}$, Pei-Yu Huang ${ }^{2}$, Chia-Ying Tu ${ }^{3}$, Cheng-Ta Chen ${ }^{1}$, Teng-Ping Tzeng ${ }^{1}$, and \\ Chao-Tzuen Cheng ${ }^{2}$ \\ ${ }^{1}$ Department of Earth Sciences, National Taiwan Normal University, Taipei City, Taiwan, R.O.C. \\ ${ }^{2}$ National Science and Technology Center for Disaster Reduction, New Taipei city, Taiwan, R.O.C. \\ ${ }^{3}$ Research Center for Environmental Change, Academia Sinica, Taipei City, Taiwan, R.O.C.
}

Received 21 July 2015, revised 31 March 2016, accepted 13 June 2016

\begin{abstract}
A High Resolution Atmospheric Model (HiRAM) at 20-km resolution is adopted to simulate tropical storm (TS) activity over the western North Pacific (WNP) and Taiwan/East Coast of China (TWCN) at the present time (1979 - 2003) and future climate (2075 - 2099) under the Intergovernmental Panel on Climate Change (IPCC) fifth assessment report (AR5) representative concentration pathway (RCP) 8.5 scenarios. The results show that in contrast to TS simulation activities in most of the low-resolution climate models, TS activities except intensity over the WNP and TWCN region are well simulated by HiRAM at 20-km resolution. The linkage between large-scale environments and TS genesis simulated by HiRAM are dramatically superior to those in low-resolution fifth Coupled Model Intercomparison Project (CMIP5) models. During 2075 - 2099, both TS genesis numbers and TS frequency over the WNP and TWCN are projected to decrease consistent with the IPCC AR5 report. However, the rate of decrease (49\%) is much greater than that projected in IPCC AR5. The decrease in TC genesis numbers under global warming is primarily attributed to the reduction in mid-level relative humidity and large-scale ascending motion, despite the warmer sea surface temperature (SST) providing more favorable conditions for TS formation. TS intensity and the maximum precipitation rate are projected to increase under global warming. At the end of the $21^{\text {st }}$ century, the mean precipitation rate within $200 \mathrm{~km}$ of TS storm center over the TWCN region is projected to increase by $54 \%$.
\end{abstract}

Key words: Tropical storm, High Resolution Atmospheric Model (HiRAM), Future projection, Global warming

Citation: Tsou, C. H., P. Y. Huang, C. Y. Tu, C. T. Chen, T. P. Tzeng, and C. T. Cheng, 2016: Present simulation and future typhoon activity projection over western North Pacific and Taiwan/East Coast of China in 20-km HiRAM climate model. Terr. Atmos. Ocean. Sci., 27, 687-703, doi: 10.3319/ TAO.2016.06.13.04

\section{INTRODUCTION}

Extreme rainfalls and flood disasters in Taiwan are contributed mainly by the passage of typhoons that are formed in the western North Pacific (WNP) and propagated northwestward by the large-scale flow. The rainfall associated with typhoons is also an important water resource in Taiwan. The potential changes in typhoon frequency, intensity and precipitation over the WNP under global warming are an interesting scientific issue and also important economic and social issues for Taiwan and Asian coastal communities.

\footnotetext{
* Corresponding author

E-mail:chi@ntnu.edu.tw
}

The effects of global warming on tropical cyclones (TCs) have been investigated and updated by many studies (e.g., Emanuel et al. 2008; Knutson et al. 2010, 2013; Murakami and Sugi 2010; Murakami et al. 2011, 2012, 2014; Ying et al. 2012; Camargo 2013; Emanuel 2013), since Intergovernmental Panel on Climate Change (IPCC) fourth assessment report (AR4) (IPCC 2007) published in 2007. Based on the fifth Coupled Model Intercomparison Project (CMIP5) projection, IPCC fifth assessment report (AR5) (IPCC 2013) summarized that consistent with the IPCC AR4 assessment, global TC frequency was estimated to decrease at the end of $21^{\text {st }}$ century. However, TC frequency changes for individual basins show large variations among different modeling studies (IPCC 2013). 
Although the thermodynamic effects of global sea surface temperature (SST) warming and increased moisture are favorable to TC activities, the regional dynamic effects such as enhanced vertical wind shear may provide unfavorable conditions for TC activities (e.g., Vecchi and Soden 2007; Knutson et al. 2010). The opposing thermodynamic and dynamic effects in individual basins may cause uncertainty and difficulty in future regional scale TC projections (Grossmann and Morgan 2011).

Another potential uncertainty in future TC activity projections may result from low-resolution model bias in CMIP5 models (Camargo 2013; Murakami et al. 2014). The resolutions of typical global climate models may be inadequate for meaningful TC intensity and structure simulations (e.g., Sugi et al. 2002; Yoshimura et al. 2006; Knutson et al. 2007). Most of the CMIP 5 models underestimated TC frequency and TC intensity over the WNP and the globe (Yokoi et al. 2012; Camargo 2103). Camargo (2013) found that among the 14 CMIP5 models analyzed, the model with the highest horizontal resolution performed the best on global TC activity. The difficulty and uncertainty of future TC projections in individual basins may be attributed to both computational limitations and the opposing thermodynamic and dynamic effects (Grossmann and Morgan 2011).

To reduce the uncertainty from climate model bias a few studies attempted to use dynamic and/or dynamicstatistical downscaling approaches with high-resolution regional models to simulate TC activity (e.g., Knutson et al 2010, 2013; Murakami et al. 2012; Emanuel 2013). In general, these studies projected an increase in TC intensity with A1B (IPCC 2007) or representative concentration pathway (RCP) 8.5 (IPCC 2013) emission scenarios. However, the changes in the number of TCs projected in individual basins are less consistent between these high-resolution modeling studies. Murakami et al. (2012) projected a significant reduction in both TC genesis number and frequency of occurrence over the WNP with A1B emission scenarios during 2075 - 2099, while Emanuel (2013) showed that both the frequency and intensity of TCs were projected to increase in the WNP using a dynamic-statistical downscaling approach with RCP 8.5 (IPCC 2013) emission scenarios.

The change in TC frequency over the WNP under global warming remains uncertain. Few studies have addressed the physical mechanisms responsible for the changes in TC activity with IPCC AR5 new emission scenarios using reliable high-resolution models. The purpose of this study is to investigate how and why TC changes occur in the WNP in a warmer climate RCP 8.5 scenario using a High Resolution Atmospheric Model (HiRAM) at $20 \mathrm{~km}$ horizontal resolution. In addition, the genesis potential index (GPI) originally developed by Emanuel and Nolan (2004) and modified by Murakami and Wang (2010) is adopted to examine the physical mechanisms responsible for the changes in TC number. The remainder of this paper is organized as follows: Section
2 introduces the datasets; section 3 introduces the HiRAM simulation design and the detection algorithm for tropical storm (TS) in HiRAM; section 4 presents the present simulation assessment and future projection of typhoon activity over WNP; section 5 presents the simulation and projection of the TS landfall and the TS activity within Taiwan/East Coast of China (TWCN) regions; section 6 discusses the dynamic and thermodynamic factors associated with TS formation. A summary of the results is given in section 7 .

\section{DATA}

The National Centers for Environmental Prediction (NCEP) Climate Forecast System Reanalysis (CFSR; Saha et al. 2010) from 1979 - 2003 are used to examine largescale circulations over the WNP. The horizontal resolutions of these thermodynamic and dynamic variables are $0.5^{\circ} \mathrm{lon}$ gitude by $0.5^{\circ}$ latitude. The monthly mean Hadley Center SST at a resolution of $1^{\circ} \times 1^{\circ}$ (Rayner et al. 2003) is also used in this study.

The 6-hourly best-track data for TCs published by the Joint Typhoon Warning Center (JTWC 2008) are obtained to examine TS activity. Only TCs with a maximum wind speed exceeding $17 \mathrm{~m} \mathrm{~s}^{-1}$ (intensity of TSs) are considered in calculating TS activity. In addition, TS formation locations are restricted to the regions from $0-35^{\circ} \mathrm{N}$ and from $100-190^{\circ} \mathrm{E}$.

Three hourly precipitation data from Tropical Rainfall Measuring Mission (TRMM, Liu et al. 2012) 3B42 V6 data are used to estimate the rainfall associated with TS. The satellite precipitation retrievals data resolution is $0.25^{\circ}$.

\section{MODEL AND METHODS}

\subsection{Model Simulation Design}

The HiRAM, originally developed by the Geophysical Fluid Dynamics Laboratory (GFDL) is adopted to simulate TC activities with horizontal resolutions of about $0.23^{\circ}$ longitude by $0.23^{\circ}$ latitude. This model utilizes hydrostatic finitevolume cubed-sphere dynamic core (Putman and Lin 2007; Harris and Lin 2013). All simulations use 32 vertical levels as in Zhao et al. (2009) and have a constant-pressure top at $10 \mathrm{hPa}$. Other model formulation details are described in the studies of Zhao et al. (2009) and Chen and Lin (2011).

A time slice method (Bengtsson et al. 1996) is applied in this study in which the high resolution atmospheric general circulation model (AGCM) is forced using prescribed SSTs as the lower boundary condition. This study simulates the typhoon activity at the present time $(1979-2003)$ and future (2075 - 2099) projections. The present time simulation is based on the Atmospheric Model Intercomparison Project (AMIP) type. The lower SST boundary conditions and sea ice concentration (SIC) in the future projection are obtained from a CMIP5 multimodel ensemble mean under the RCP 8.5 scenarios. The inter-annual variations in SST 
and SIC in the future are assumed to be similar to those of the present time.

\subsection{Detection Algorithm for TS}

The objective algorithm developed by Vitart (1997, 2003) and Knutson et al. (2007) is adopted to identify TSs in the model. The criteria used in this study are similar to those used in Knutson et al. (2007) but with some modifications. This objective algorithm includes two steps, which are Potential storm identification and Storm tracking. The criteria for these two steps used in this study are described as follows.

Potential storm identification: The TS detection algorithm first locates the position of intense vortices with a warm core for each 6-hour period as follows.

(1) The maximum relative vorticity at the $850 \mathrm{hPa}$ exceeds $1.5 \times 10^{-4}$.

(2) The closed minimum sea level pressure is defined as the center of the storm.

(3) The closest local maximum average temperature between 500 and $300 \mathrm{mb}$ is located and defined as the center of the warm core.

(4) The maximum wind speed at $10 \mathrm{~m}$ exceeds $17.5 \mathrm{~m} \mathrm{~s}^{-1}$.

Storm tracking: After storms are located for each 6-hour period, an objective procedure is applied to find the storm trajectories as follows.

(1) For each storm, we examine whether there are storms that appear in the following 6-hour time period within a distance less than $750 \mathrm{~km}$.

(2) To be considered as a model TS trajectory, a trajectory must last at least 3 days.

\section{PRESENT SIMULATION AND FUTURE PROJECTION OVER THE WNP}

This study assessed typhoon activity at the present time (1979 - 2003) and future (2075 - 2099) projections under the IPCC RCP 8.5 scenarios using the HiRAM. The TS activity examined in this study includes TS numbers, TS track, TS intensity, and TS landfall.

\subsection{TS Numbers}

The seasonal cycle of TS numbers in the WNP for 1979 - 2003 is shown in Fig. 1. TS numbers increase significantly from June with a peak in August (Fig. 1). The seasonal cycle of TS numbers is well captured by HiRAM (Fig. 1), although HiRAM overestimates the TS numbers in agreement with the study of Zhao et al (2009) using HiRAM at $50 \mathrm{~km}$ resolution. The correlation coefficient between the simulated and observed seasonal cycle of TS numbers is 0.94 . At the end of the $21^{\text {st }}$ century, TS numbers are projected to significantly decrease from June to November
(JJASON) in the future projection (Fig. 1).

We focus on TS activities in the TS active season from JJASON in this study. Figure 2 depicts the TS formation frequency spatial distribution during JJASON. The average number of TSs during summer and fall is 23 per year (Fig. 2a), which accounts for $84 \%$ of the annual total TS number. The climatological mean of the TS number simulated from HiRAM during JJASON is 27 (Fig. 2b). Although HiRAM overestimates the TS numbers, the TS formation frequency spatial distribution is well captured by HiRAM (Fig. 2b).

Although TS numbers are projected to decrease by the majority of CMIP3 and CMIP5 models (IPCC 2013), the change rates in TS genesis frequency in coarse resolution CMIP3 and CMIP5 models range broadly from -70 to $+60 \%$ (Ying et al. 2012). There are better agreements in the TS number change projection in the WNP among the limited studies using high-resolution models. The TS frequency change rate projected by high-resolution models under A1B (e.g., Murakami et al. 2012, 2014) and RCP 4.5 (Knutson et al. 2015) scenarios are confined from $-20 \%$ to $-35 \%$. Under the strongest warming scenario RCP 8.5 used in this study, the TS formation frequency is projected to significantly decrease by -49\% during 2075 - 2099 (Fig. 2c). The decrease in total TS frequency is contributed mainly by the significant decrease in TS frequency over the southern part of the WNP region (Fig. 2c).

To explore the relationship between TS formation and large-scale circulation, the TS formation frequency spatial distribution and large-scale circulation during typhoon peak season from July to September (JAS) are depicted in Fig. 3. Most TS are formed in the monsoon trough (Fig. 3a) and the easterly and westerly convergence region where the easterlies and westerlies converge (Fig. 3a). The dynamic link between large-scale circulation and TS formation in autumn is similar

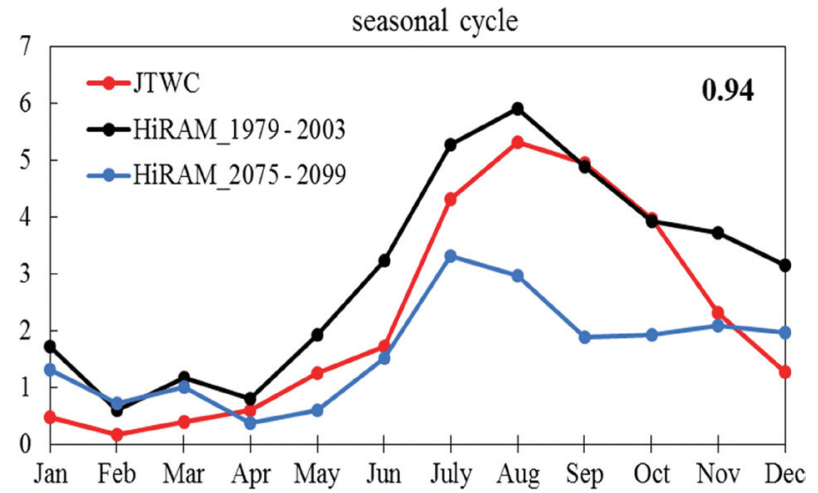

Fig. 1. Seasonal cycle of TS genesis frequency (unit: number of TS per month per year) for observation (red line), HiRAM model simulation during 1979 - 2003 (black line), and HiRAM projection during 2075 - 2099 (blue line). The number in the upper corner is the correlation coefficient between the HiRAM simulation (black line) and observation (red line). 

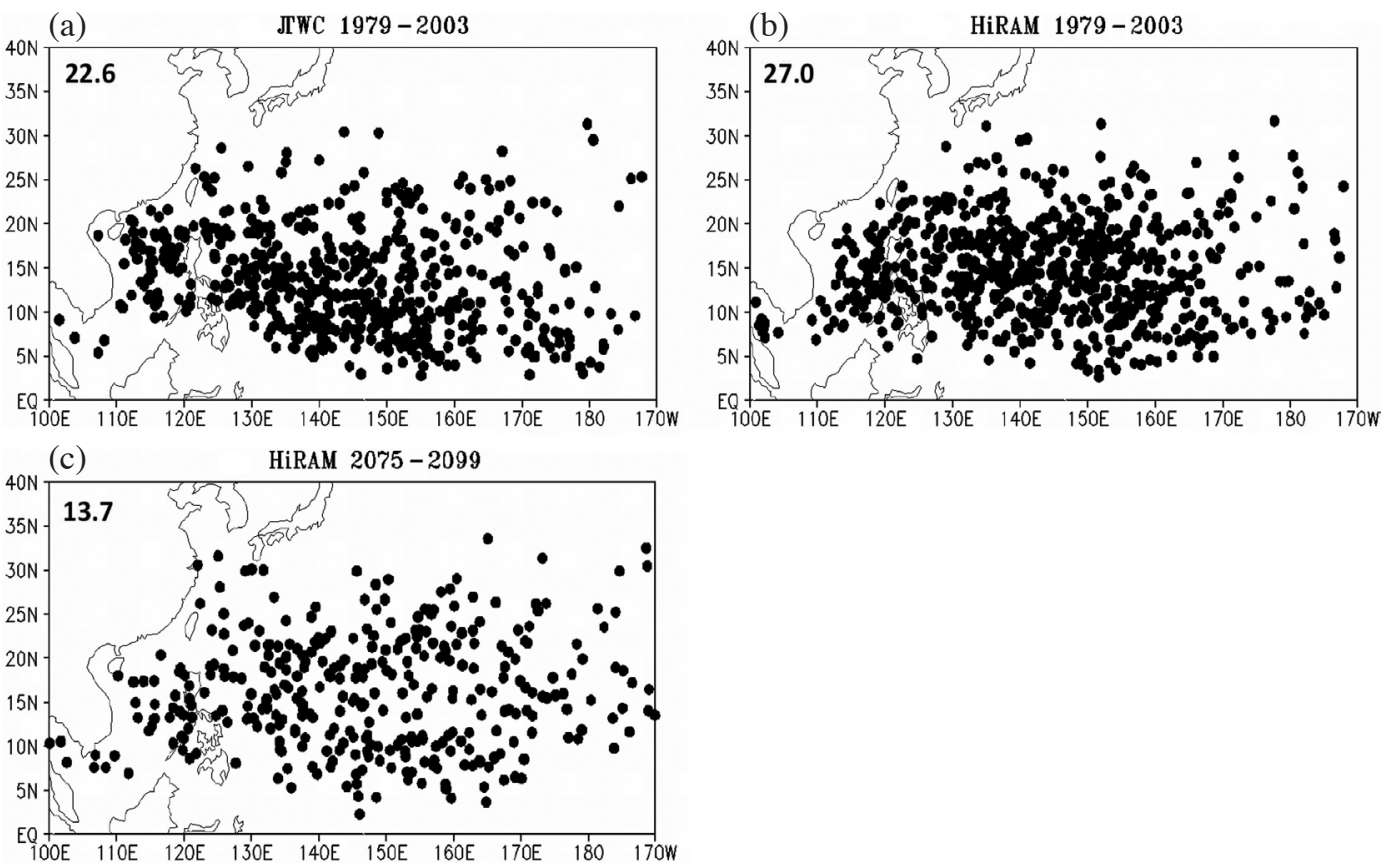

Fig. 2. TS formation location distribution (dots) from June to November (JJASON) for the period 1979 - 2003 in (a) JTWC and (b) HiRAM. (c) same as (b), but for the period 2075 - 2099. The numbers in the upper corners are TS total numbers (unit: numbers per year).
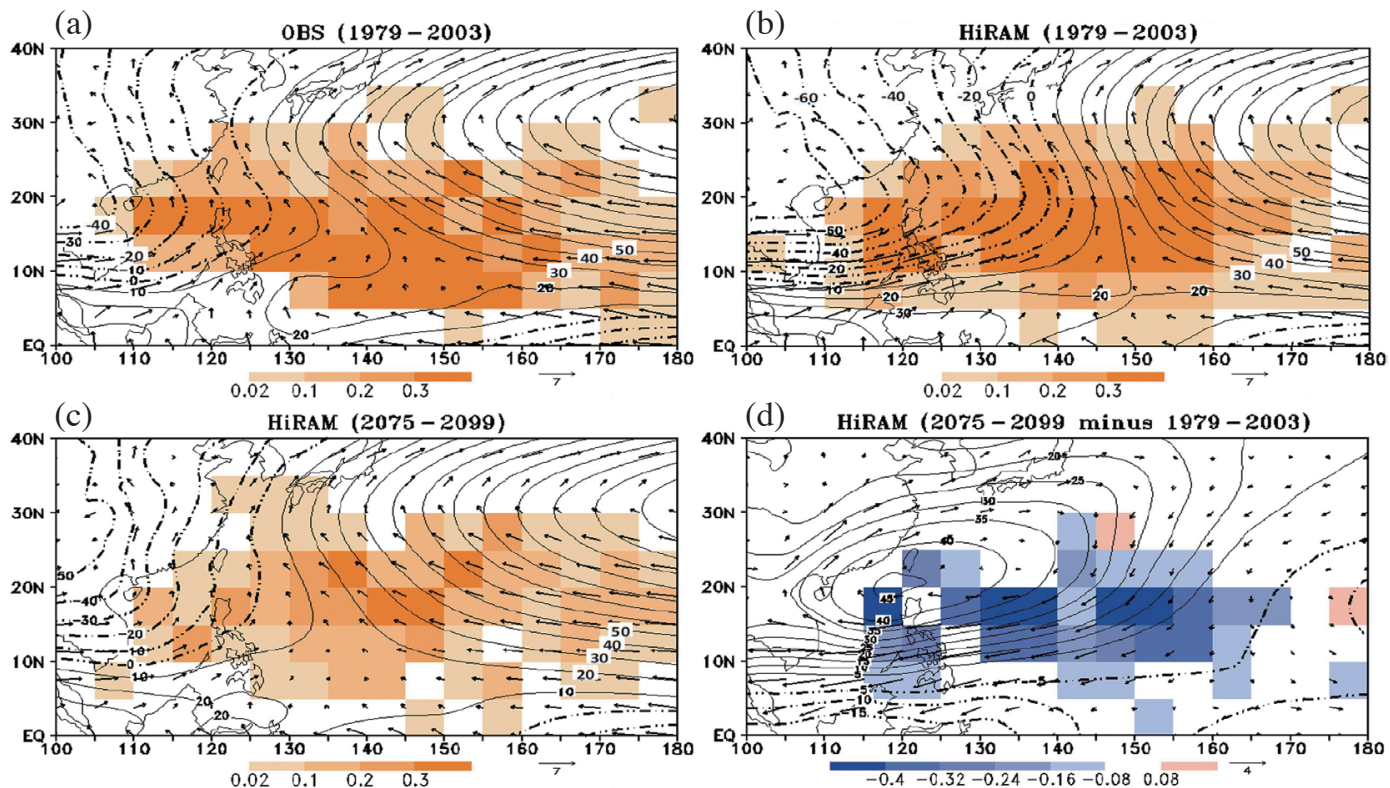

Fig. 3. TS formation frequency distribution (shaded, unit: numbers per $5^{\circ}$ longitude/latitude per year), $850 \mathrm{hPa}$ wind fields $\left(\mathrm{m} \mathrm{s}^{-1}\right)$ and $850 \mathrm{hPa}$ stream function (contour, unit: $10^{5} \mathrm{~m}^{2} \mathrm{~s}^{-1}$ ) during JAS for the period 1979 - 2003 for (a) observation, (b) HiRAM. (c) same as (b), but for the period 2075 2099. (d) Difference between the present and future projection in HiRAM (2075 - 2099 minus 1979 - 2003).

to that in summer (not shown) except that the monsoon trough in summer is replaced by a strong cyclonic circulation over the WNP in autumn (Tsou et al. 2014). These results indicate that the monsoon trough and low-level convergence are vital factors for TS formation and development (Holland 1995; Kuo et al. 2001; Tam and Li 2006; Tsou et al 2014).
The TS formation frequency spatial distribution and gross monsoon trough features, subtropical high and convergence region are well captured by HiRAM (Fig. 3b). Simulated TS in HiRAM are also formed in the monsoon trough and zonal wind convergence region (Fig. 3b). Compared to the observations, the simulated monsoon trough is 
stronger than the observations consistent with greater TS formation number in HiRAM.

Compared to the present time, the monsoon trough will weaken, while the subtropical high will be enhanced (Fig. 3c). Associated with the monsoon trough weakening, an anomalous anticyclone circulation will occur to the north of the Philippines in the future which will suppress the formation and development of TSs (Fig. 3d). These features imply that the large-scale circulation may induce an unfavorable environment for TS formation in the future, although SST warming provides a favorable condition for TS formation in the future global warming world. The thermodynamic and dynamic conditions responsible for the TS numbers decreasing in the future warming world will be further investigated in section 6 .

\subsection{TS Track and Frequency}

Figure 4 depicts the TS track and frequency for observation, present simulation, and future projection. TS frequency is estimated by the total number of TSs passing over a $2.5^{\circ} \times 2.5^{\circ}$ grid box. In general, TS tracks over the WNP can be classified into three typical tracks (Fig. 4a): westward, northwestward, and northeastward recurving (e.g., Ho et al. 2004; Wu and Wang 2004; Camargo et al. 2007). The primary TS frequencies coincide with the monsoon trough (Figs. 3a, 4d), since most of TS are formed and developed along the monsoon trough.

The gross TS track and TS frequency features are well simulated by HiRAM, (Figs. 4b and e), although the TS frequency pattern in HiRAM shifts slightly to the east of the observation (Fig. 4e). The spatial pattern correlation coefficient between the simulation and observation TS frequency over the WNP $\left(110-180^{\circ} \mathrm{E}, 0-40^{\circ} \mathrm{N}\right)$ is 0.83 .

Accompanied by the reduction in TS formation numbers, all three types of TS tracks will be reduced in the future projection (Fig. 4c). Murakami et al. $(2012,2014)$ found that TS frequency will shift eastward under A1B scenario, resulting in a reduction in TS frequency in the western part of the WNP. However, in this study, TS frequency over the entire WNP region will be reduced significantly (Figs. $4 \mathrm{f}$ and $\mathrm{g}$ ) consistent with the dramatically decreasing TS formation numbers in the future over the WNP.

\subsection{TS Intensity}

TS intensities recorded by JTWC and simulated by HiRAM are defined as the maximum 1-min mean sustained wind speeds and maximum instantaneous wind speeds at $10-\mathrm{m}$ height, respectively. The inconsistency in the definition of TC intensity between JTWC (1-min mean sustained wind speeds) and other datasets (10-min mean sustained wind speeds) was noted by Simiu and Scanlan (1978). They found that the strength of the 10-min mean sustained wind speeds is statis- tically $88 \%$ of the 1 -min mean sustained wind speeds. The differences between the instantaneous wind speed strength from the models and 1-min (or 10-min) mean sustained wind speeds from the observations have not been addressed in the literature. It is possible that instantaneous wind speeds are greater than the 1-min mean sustained wind speeds.

TS intensity is classified into 5 categories based on the Saffir-Simpson Hurricane intensity scale (Simpson and Riehl 1981). Figure 5 displays the frequency of Category 1 to 5 storms. The majority of the TSs are weak TSs (Category 1 and 2) or intense TSs (Category 4 and 5). HiRAM overestimates the number of weak TSs, while seriously underestimates the intense TSs (Fig. 5a). Therefore, HiRAM underestimates the mean lifetime maximum intensity (LMI; the maximum intensity achieved during a storm's lifetime). HiRAM at $20 \mathrm{~km}$ horizontal resolution is unable to simulate the Category 4 and 5 storms, which is similar to the findings of other high-resolution model studies (e.g., Knutson et al. 2008, 2013; Bender et al. 2010; Murakami and Sugi 2010).

The decrease in the total TS numbers in future projections (Fig. 2c) is contributed mainly by the decrease in Category 1 to 3 storms (Fig. 5b). On the contrary, the frequency of Category 4 TSs is projected to increase in the future. In addition, HiRAM may underestimate the number of Category 5 TS in the future, since HiRAM is unable to simulate Category 4 and 5 TS. Thus, the mean LMI is only projected to increase slightly.

The mean TS wind speed distribution over the WNP is shown in Fig. 6. The mean TS wind speed is determined by the mean wind speed of TSs passing over each $2.5^{\circ} \times 2.5^{\circ}$ grid box. The greatest mean TS wind speed is located east of Taiwan over the region $\left(120-140^{\circ} \mathrm{E}, 15-30^{\circ} \mathrm{N}\right.$, Fig. $\left.6 \mathrm{a}\right)$. The gross feature of the mean TS wind speed spatial distribution is well simulated by HiRAM, although the mean wind speed simulated from HiRAM is slightly weaker than the observations (Fig. 6b). The pattern correlation between the mean wind speed simulation and observation distributions over the WNP is 0.78 .

TS mean wind speed is projected to significant increase over the East Asian Coast Area (west of $130^{\circ} \mathrm{E}$, Figs. $6 \mathrm{c}$ and d), especially for the region near and north of Taiwan, while TS mean wind speed is projected to change slightly or decrease over the ocean south of $20^{\circ} \mathrm{N}$. The significant increase in TS wind speed over the East Asian Coast area is in agreement with the projection by Emanuel (2013) which projected a significant increase in the power dissipation index over the East Asian Coast. This indicates that the intensity of the northwestward moving and recurved TS will increase at the end of the $21^{\text {st }}$ century, although the TS numbers will reduce.

\subsection{TS Rainfall}

TS often bring heavy rainfall especially in the eye wall 

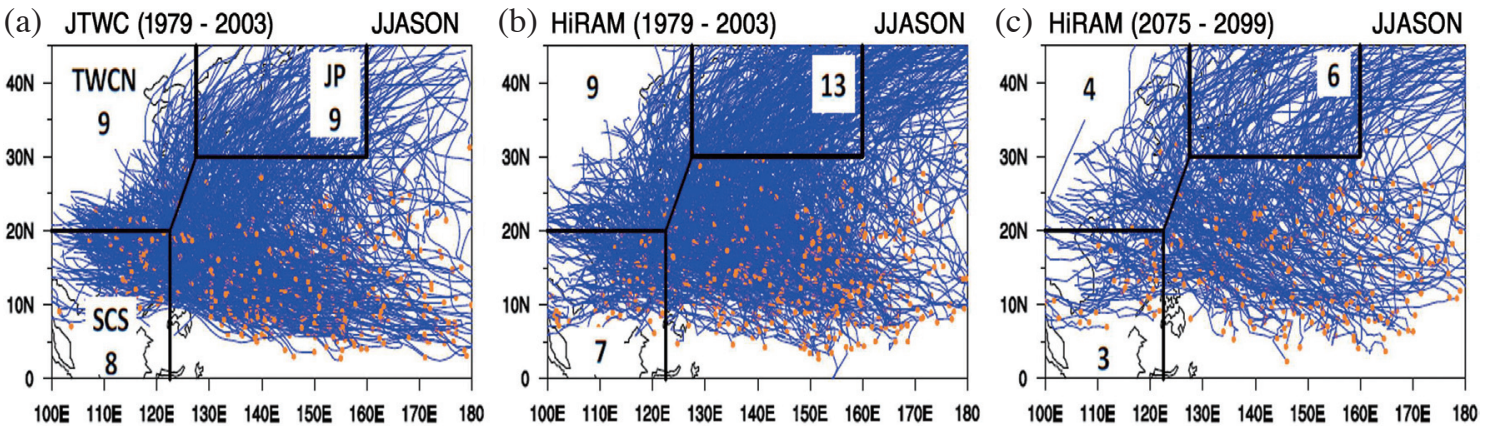

(d)

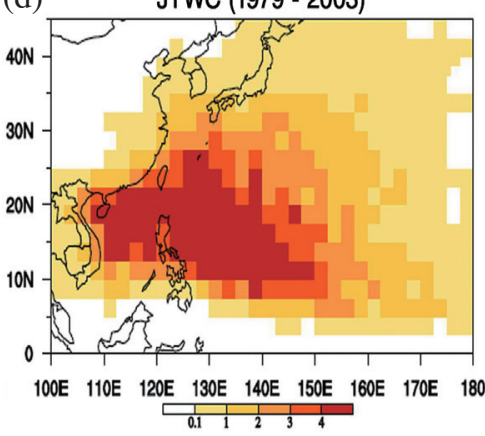

(e)

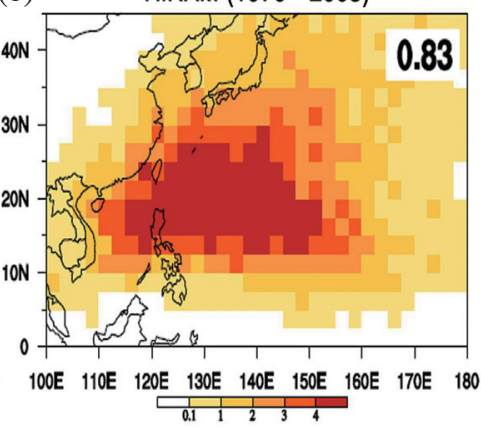

(f)

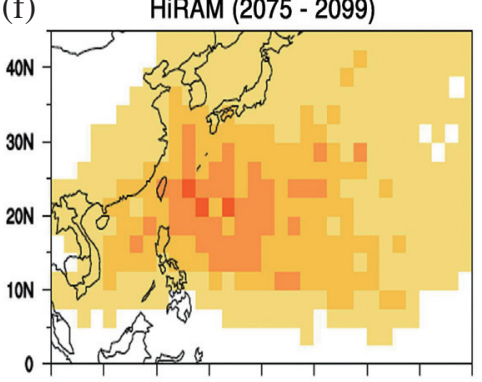

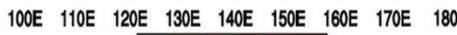

(g) HiRAM (2075 - 2099 minus 1979 - 2003)

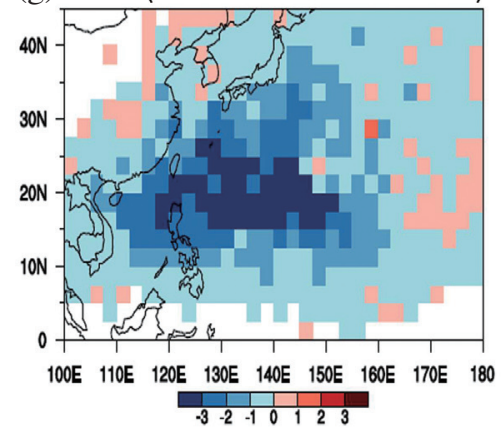

Fig. 4. TS tracks and TS frequency during JJASON for the period 1979 - 2003 for (a) JTWC and (b) HiRAM. (c) same as (b), but for the period 2075 - 2099. (d) - (f) TS frequency (numbers per $2.5^{\circ}$ longitude/latitude per year). (g) Difference between the present and future projection in HiRAM (2075 - 2099 minus 1979 - 2003). Black lines in (a) - (c) show the boundaries of three landfall regions classified in this study. The characters TWCN, SCS, and JP represent Taiwan and the east coast of China (TWCN), the South China Sea region (including Philippines, SCS), and the Japan (JP) landfall regions, respectively. The numbers in each box are the number of TSs affecting each region (numbers per year). The number in the upper corner of (e) is the pattern correlation coefficient between HiRAM experiments and observation.
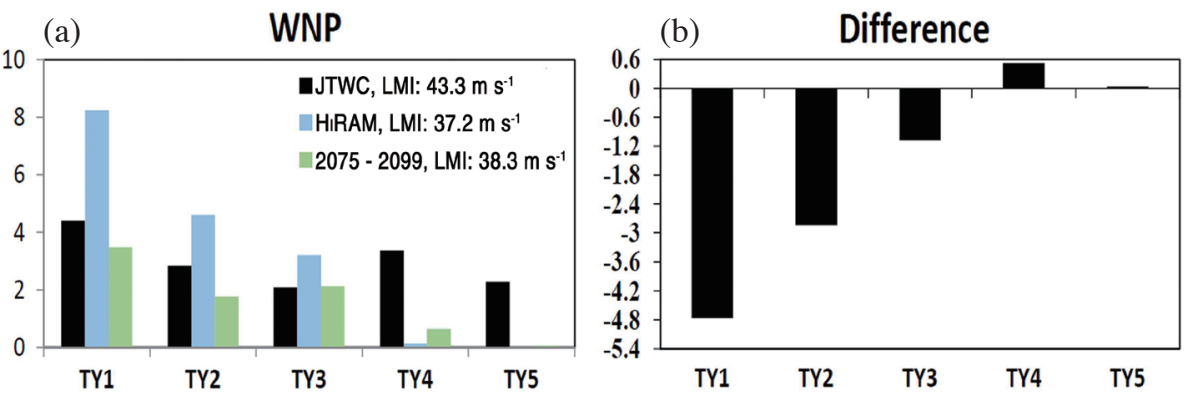

Fig. 5. (a) The frequency (unit: numbers per year) of Category 1 to 5 storms for observation and HiRAM during JJASON for the period 1979 - 2003 , and HiRAM for the period 2075 - 2099. (b) Projection changes in the TS number (2075 - 2099 minus 1979 - 2003) for HiRAM. The number in the upper corner of (a) is the mean LMI (the maximum intensity achieved during a storm's lifetime) for observation, HiRAM, and future projection, respectively. 
(a)

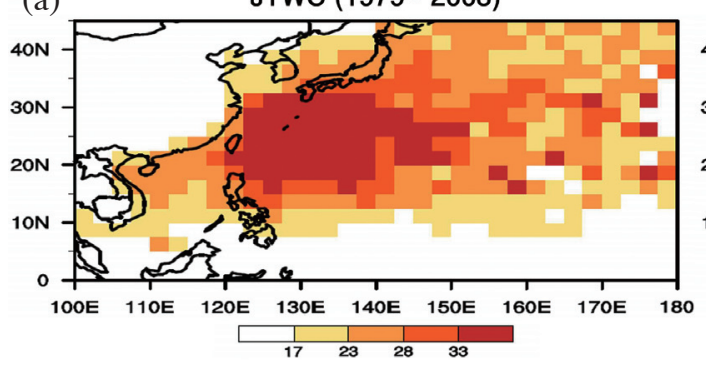

(c)

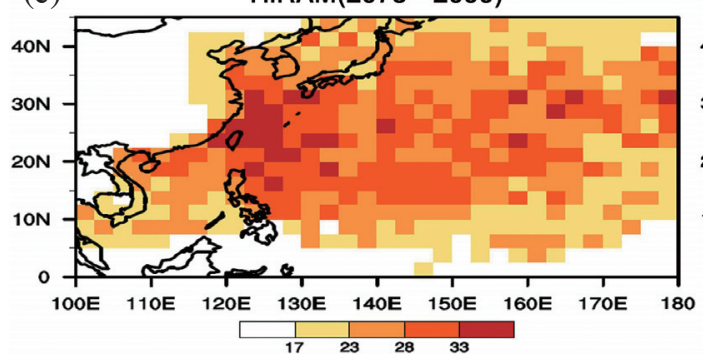

(b)

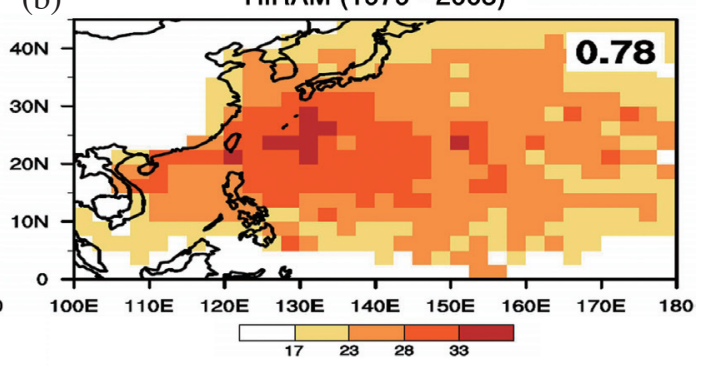

(d) 2075 - 2099 minus $1979-2003$ contour trom -3 to 3 by 1

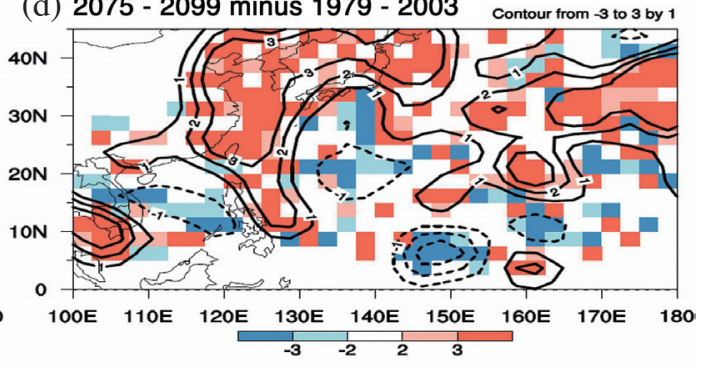

Fig. 6. TS intensity distribution (unit: $\mathrm{m} \mathrm{s}^{-1}$ per $2.5^{\circ}$ longitude/latitude per year) during JJASON for the period 1979 - 2003 for (a) observation, (b) HiRAM. (c) same as (b), but for the period 2075 - 2099. (d) Difference between the present and future projection in HiRAM (2075-2099 minus 1979 - 2003).

regions. To determine the maximum rainfall associated with TS we estimate the maximum precipitation rate within $200 \mathrm{~km}$ of the storm center at the LMI time. A composite of the maximum precipitation rate for all TSs is shown in Fig. 7. The observational precipitations generally possess a symmetrical structure in their inner core (Fig. 7a), without detailed eye wall and rain band structure. The maximum precipitation rate is located within $100 \mathrm{~km}$ of the storm center. This may be partially due to the satellite retrieval limitation and composite of different TSs. HiRAM captures the rainfall spatial distribution with stronger inner structure (Fig. 7b), including a clearly discernible eye at the storm center and asymmetrical rain bands surrounding the storm.

During 2075 - 2099, the mean precipitation rate within $200 \mathrm{~km}$ of TSs over the WNP is projected to increase in a warmer climate (Fig. 7c). The average rain rates within 200 and $100 \mathrm{~km}$ are projected to increase by 22 and $23 \%$, respectively. This result is in agreement with the findings of previous studies using high-resolution models (e.g., Knutson et al. 2010, 2013; Lin et al. 2015). The increase of rainfall is consistent with the warming of SST. Warmer SST will produce greater rainfall associated with TS (Lin et al. 2015).

\subsection{Summary of Simulation and Projection of TS Activity over the WNP}

The simulation and projection of typhoon activity over the WNP is summarized in Table 1. HiRAM overestimates the number of TSs over the WNP (column 1 in Table 1). However, the spatial distribution of TS formation and frequency are well simulated by HiRAM (column 2 in Table 1).
The simulated TS genesis numbers and TS frequency distribution by HiRAM at $20 \mathrm{~km}$ are significantly better than those predicted by low-resolution CMIP5 models (Camargo 2013). The TS number is projected to decrease at the end of the $21^{\text {st }}$ century (column 1 in Table 1) in agreement with previous studies (e.g., Zhao et al. 2009; Murakami et al. 2012, 2014; Ying et al. 2012). The rate of change $-49 \%$ is much greater than that in the IPCC AR5 report (IPCC 2013). The TS frequency change projection over the WNP remains uncertain.

HiRAM overestimates the number of weak TSs (column 3 in Table 1), while it seriously underestimates the number of intense TSs (column 4 in Table 1). Therefore, the simulated mean LMI (the maximum intensity achieved during a storm's lifetime) is weaker than the observations (column 5 in Table 1). This intensity simulation feature is similar to that in previous results using high-resolution models with IPCC AR4 scenarios (e.g., Knutson et al. 2008, 2013; Bender et al. 2010; Murakami and Sugi 2010). HiRAM at $20 \mathrm{~km}$ is unable to simulate Category 4 and 5 TSs. During 2075 - 2099, weak TSs are projected to decrease significantly (column 3 in Table 1), which results in a significant decrease in the TS numbers, while the number of intense TSs are projected to increase (column 4 in Table 1).

The maximum mean precipitation rate within $200 \mathrm{~km}$ of the storm center at LMI time is estimated and composited (column 6 in Table 1). Due to satellite retrieval limitations, the mean maximum precipitation rate of observation may be underestimated (column 6 in Table 1). At the end of the $21^{\text {st }}$ century, the mean precipitation rate within $200 \mathrm{~km}$ of the storm center at LMI time in the WNP is projected to increase by $22 \%$. 

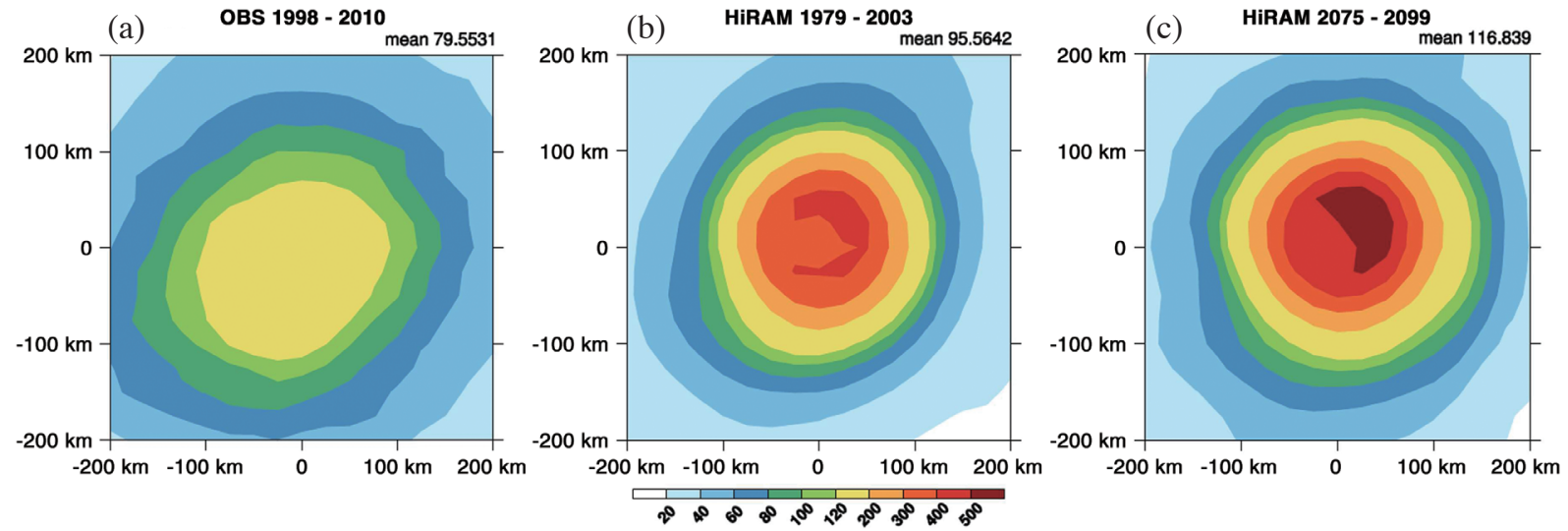

Fig.7. Composite of the maximum precipitation rate for all TSs within $200 \mathrm{~km}$ of the storm center at the time of the LMI during JJASON for the period 1979 - 2003. LMI the maximum intensity achieved during a storm's lifetime. For (a) observation, (b) HiRAM. (c) same as (b), but for the period 2075 - 2099.

Table 1. Comparisons of HiRAM simulated TS activity with observations during 1979 - 2003, and future projections during 2075 - 2099. PC is the pattern correlation coefficient between simulation TS frequency and observation $\left(110-180^{\circ} \mathrm{E}, 0-40^{\circ} \mathrm{N}\right)$. LMI the maximum intensity achieved during a storm's lifetime. Maximum precipitation rate (MP) is the average rain rate within $200 \mathrm{~km}$ of the storm center at the time of the LMI.

\begin{tabular}{c|cccccc}
\hline WNP & $\begin{array}{c}\text { TS Num. } \\
\text { (Num. per year) }\end{array}$ & PC & $\begin{array}{c}\text { TY1 \& TY2 } \\
\text { (Num. per year) }\end{array}$ & $\begin{array}{c}\text { TY4 \& TY5 } \\
(\text { Num. per year })\end{array}$ & $\begin{array}{c}\text { Mean LMI } \\
\left(\mathbf{m ~ s}^{-1}\right)\end{array}$ & $\begin{array}{c}\text { MP } \\
\left(\mathbf{m m ~ d a y}^{-1}\right)\end{array}$ \\
\hline JTWC & 22.6 & & 7.2 & 5.6 & 43.3 & 79.6 \\
HiRAM & 27.0 & 0.83 & 12.8 & 0.1 & 37.2 & 95.6 \\
$2075-2099$ & 13.7 & & 5.2 & 0.7 & 38.3 & 116.8 \\
\hline
\end{tabular}

\section{TS LANDFALL SIMULATION AND PROJECTION OVER TAIWAN AND THE EAST COAST OF CHINA}

\subsection{TS Landfall}

Based on the climatological TS tracks (Fig. 4a) and the study of Wu and Wang (2004), the TS landfall regions are classified into three regions: Taiwan and the east coast of China (TWCN), the South China Sea region (including Philippines, SCS), and the Japan region (JP). If TS enters the SCS and then moves to the TWCN region, it is counted as one in SCS and one in TWCN.

During the June-November period the number of TSs affecting TWCN, SCS, and the JP region are 9, 8 , and 9, respectively (Fig. 4a). TS landfall numbers over the TWCN region are well captured in the HiRAM $20-\mathrm{km}$ model. Nevertheless, HiRAM overestimates the TS landfall numbers over the JP region. It is interesting to note that the overestimation of total TS numbers in HiRAM is contributed mainly by the overestimated TS numbers that recurve east of $130^{\circ} \mathrm{E}$.

TS landfall numbers in all three regions is projected to reduce in the future projection (Fig. 4c) consistent with the dramatically decreasing TS formation numbers and frequency in the future in the WNP.

\subsection{TS Activity over Taiwan and East Coast of China}

Figure 8 depicts the TS track and frequency affecting the TWCN region. Most of the TS landfalls are formed west of $150^{\circ} \mathrm{E}$ (Fig. 8a) and then move northwestward. Thus, the greatest TS frequency is located in the region $\left(110-130^{\circ} \mathrm{E}\right.$, $15-25^{\circ} \mathrm{N}$, Fig. 8d). The gross TS tracks and TS frequency features affecting the TWCN regions are well simulated by HiRAM (Figs. 8b and e). The spatial pattern correlation coefficient between TS frequency distribution for simulation and observations over the WNP is 0.87 . Again, the TS frequency surrounding the TWCN region is projected to significantly decrease in the future (Figs. $8 \mathrm{f}$ and $\mathrm{g}$ ) due to the reduction in TS formation numbers.

The TS mean wind speed distribution affecting TWCN regions is shown in Fig. 9. The greatest TS mean wind speed is located east of Taiwan over the region $\left(120-140^{\circ} \mathrm{E}\right.$, $15-30^{\circ} \mathrm{N}$, Fig. 9a), which is similar to the maximum mean TS wind speed over the WNP (Fig. 6a). TS weaken as they approach the Asian landmass (compare Figs. 6a and 9a). The gross spatial distribution feature of the mean wind speed is well simulated by HiRAM, although the mean TS wind speed simulated from HiRAM is slightly weaker than the observations (Fig. 9b). The pattern correlation between 
the mean wind speed distribution affecting TWCN region for simulation and observations over the WNP is 0.71 .

HiRAM projects a significant increase in the mean TS wind speed (Figs. 9c and d). The location of maximum mean wind speed is projected to shift northward and westward within the TWCN region in the future period (Fig. 9c). This result indicates that the TS intensity within TWCN will increase at the end of the $21^{\text {st }}$ century, although the TS numbers will decrease.

We define a regional maximum intensity index (RMI) as the maximum intensity achieved within TWCN region to distinguish between the intensity of TS landfall within the TWCN region and the whole WNP. Figure 10 displays the RMI frequency within the TWCN region. The RMI intensity is also classified using the Saffir-Simpson Hurricane intensity scale. The majority of TSs affecting the TWCN region are weak TSs (Category 1 and 2) when they approach the Asian landmass. HiRAM well simulates the number of weak TSs, while underestimates intense TSs (Fig. 10). There are few intense TSs within the TWCN region. Thus, the RMI simulation within the TWCN region by HiRAM is better than the LMI simulations over the WNP.

The decrease in TS landfall numbers within the TWCN region in future projections are contributed mainly by the decrease in the number of weak TSs (Fig. 10). The frequency of Category 3 and 4 TSs within TWCN is projected to increase in the future.

To determine the maximum rainfall within the TWCN regions we estimate the maximum precipitation rate within $200 \mathrm{~km}$ of the storm center at RMI time. A composite of the maximum precipitation rate for all TSs affecting TWCN region is shown in Fig. 11. Despite the regional maximum wind speed (as RMI) within the TWCN region becoming weaker than that projected by LMI over the WNP, the magnitude of

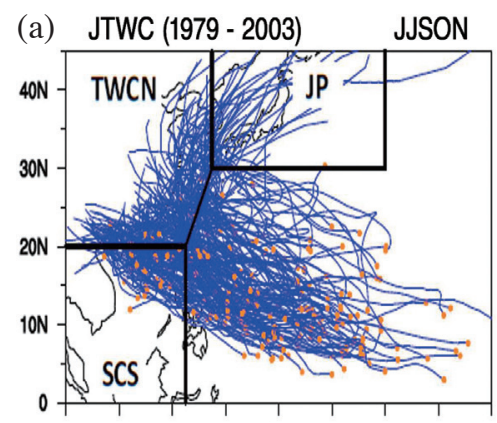

100E L10E L20E T30E 140E 150E 160E 170E 180

(d)

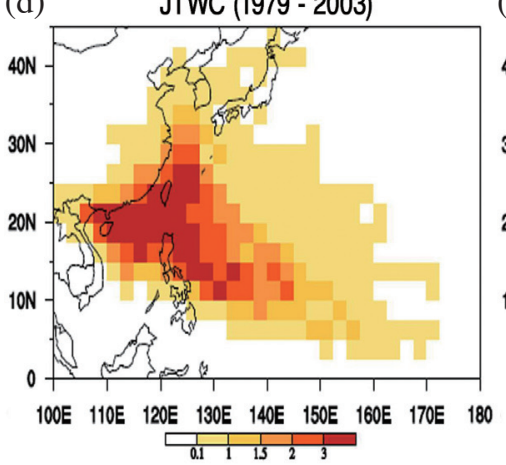

(g) HiRAM (2075 - 2099 minus 1979 - 2003)

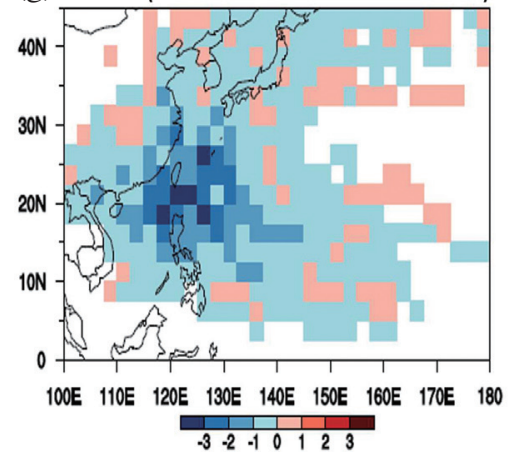

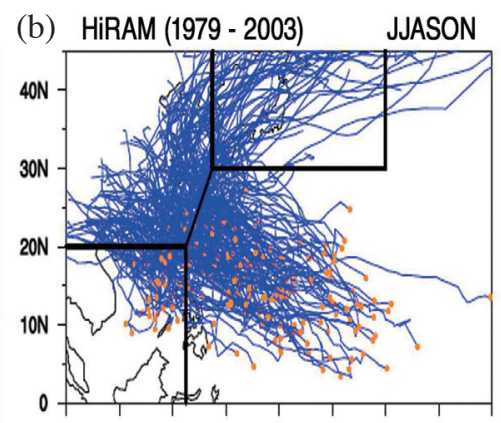

100E T10E T20E T30E 140E 150E T60E 170E 180
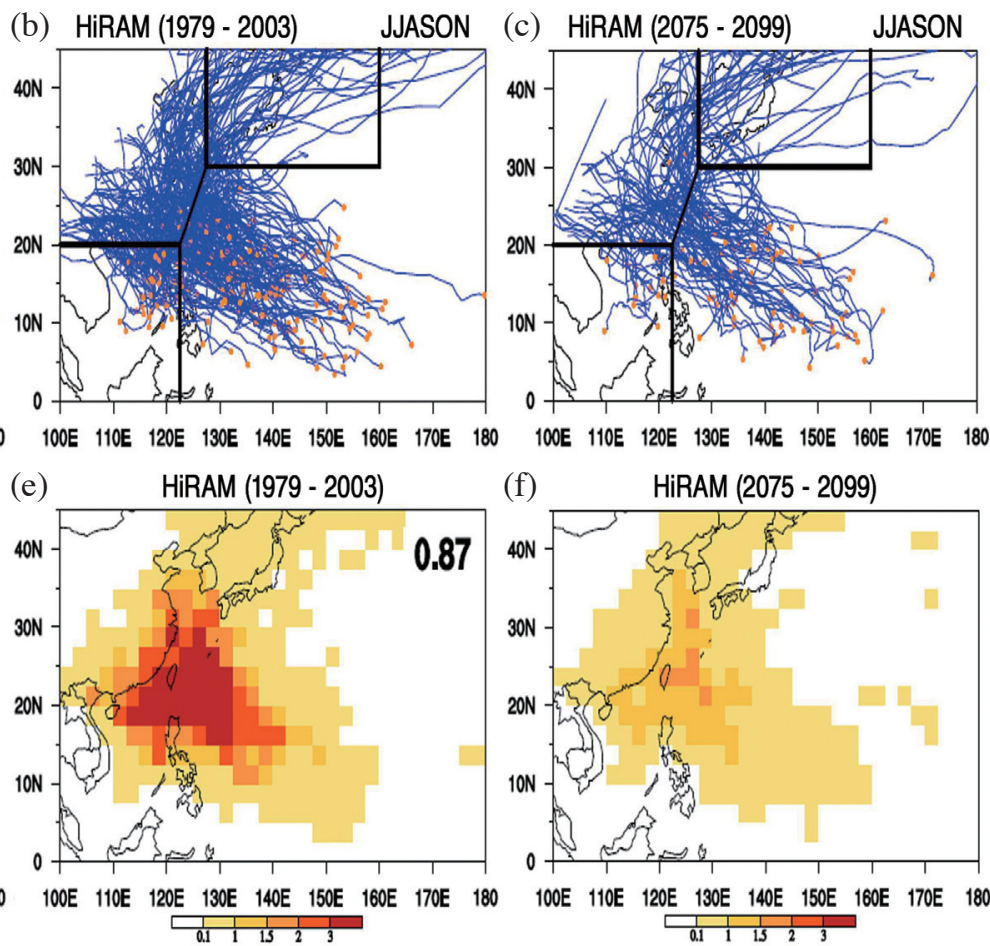

(f)

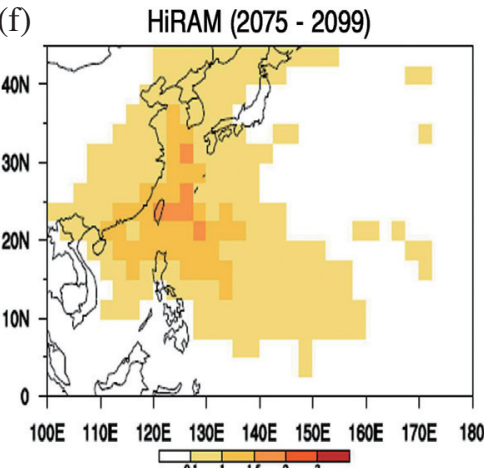

Fig. 8. Same as Fig. 4, but for TS affecting TWCN region. 

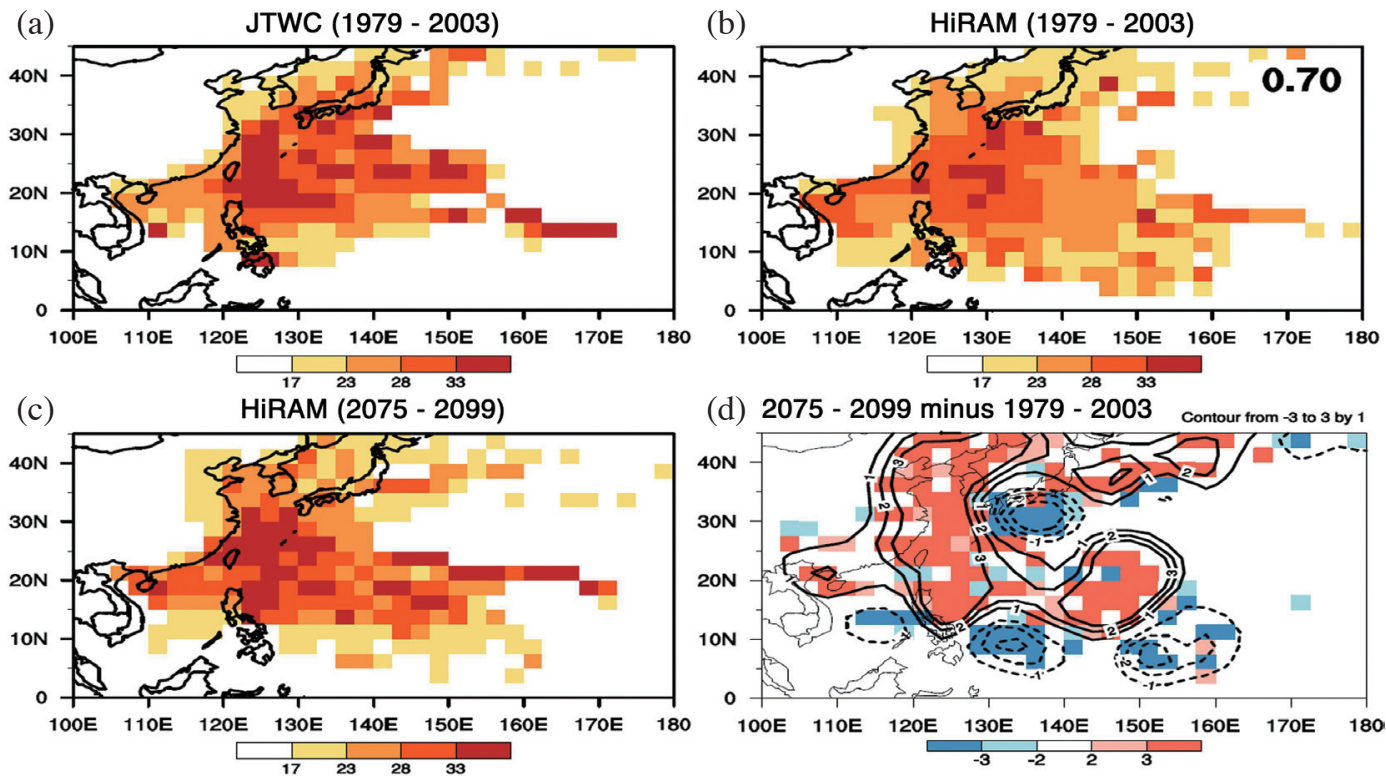

(d) 2075 - 2099 minus 1979 - 2003 contour trom - 3 to 3 by 1

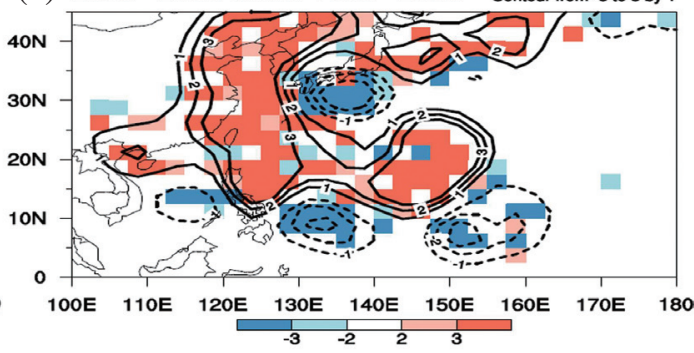

Fig. 9. (a), (b), (c), (d) same as Fig. 6, but for TS affecting TWCN region.

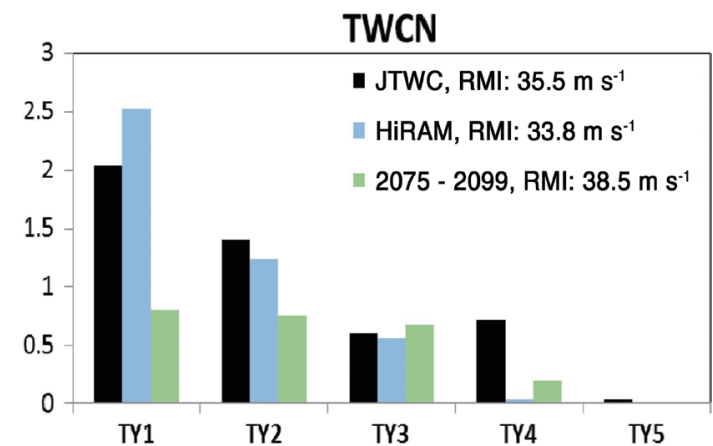

Fig. 10. Same as Fig. 5a, but for TS affecting TWCN region. TS intensity scale is determined by the maximum intensity achieved within TWCN region (RMI).
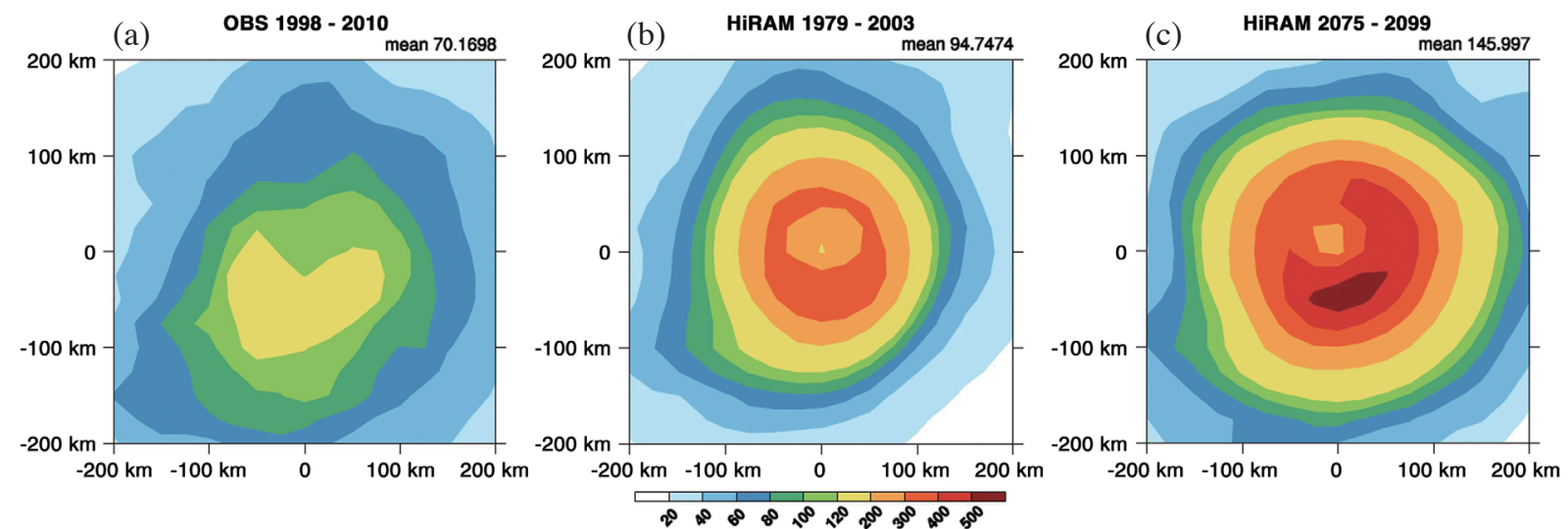

Fig. 11. (a), (b), (c) same as Fig. 7, but for TS affecting TWCN region. 
mean maximum precipitation rate in TSs within the TWCN region is comparable to that over the WNP. In addition, the observational TS precipitation within the TWCN generally possesses an asymmetric structure with heavier precipitation over the southwest quadrant (Fig. 11a). The TS precipitation within the TWCN region may be strongly influenced by large scale southwesterly flow. HiRAM captures the spatial distribution of rainfall with heavier precipitation over the southern part of the TS center (Fig. 11b).

During 2075 - 2099, the mean maximum precipitation rate within $200 \mathrm{~km}$ of TS within TWCN region is projected to increase (Fig. 11c). The average rain rates within 200 and $100 \mathrm{~km}$ are projected to increase by 54 and $50 \%$, respectively. The change rates are greater than those over the WNP. It is interesting to note that more intense heavy precipitation will be accompanied by TSs affecting Taiwan and the East Coast of China region, despite the majority of those TSs becoming weak TSs.

\subsection{Summary of Simulation and Projection of TS Activity over the TWCN}

The simulation and projection of typhoon activity over the TWCN is summarized in Table 2. The climatological mean number of TSs making landfall in the TWCN region is well simulated by HiRAM (column 1 in Table 2). The number of TSs within the TWCN region is also projected to decrease significantly during 2075 - 2099, which is consistent with the dramatic decrease in TS numbers over the WNP (column 1 in Table 1). The gross feature of the TS frequency spatial distribution affecting the TWCN region is also well simulated by HiRAM (column 2 in Table 2).

Since TSs weaken as they approach the Asian landmass and TWCN regions, a RMI as the maximum intensity achieved within TWCN region is defined and computed in this study. The RMI intensity is also classified by the Saffir-Simpson Hurricane intensity scale. The majority of TSs within the TWCN are weak TSs (columns 3 and 4 in Table 2). Therefore, the RMI within the TWCN region (RMI) (column 5 in Table 2) are weaker than the LMI (column 3 to 5 in Table 1). HiRAM well estimates the number of weak TSs, while underestimates the number of intense TSs (columns 3 and 4 in Table 2). The RMI simulation within the TWCN region by HiRAM (column 5 in Table 2) is better than the LMI simulations over the WNP (column 5 in Table 1) due to less intense TSs occurring in TWCN region. At the end of the $21^{\text {st }}$ century, weak TSs within the TWCN region are projected to decrease significantly (column 3 in Table 2), resulting in a significant decrease in the TS numbers, while the number of intense TSs is projected to increase slightly (column 4 in Table 2).

The magnitude of mean maximum precipitation rate within $200 \mathrm{~km}$ of the TS storm center at RMI time within the TWCN (column 6 in Table 2) is comparable to that over the
WNP (column 6 in Table 1). It is suggested that the largescale southwesterly may play an important role in the maximum precipitation rate of TS. At the end of the $21^{\text {st }}$ century, the mean precipitation rate within $200 \mathrm{~km}$ of TS within the TWCN region is projected to increase by $54 \%$. The change rate is greater than that over the WNP. This indicates that people within the TWCN region will be affected by more intense heavy rainfall associated with TSs in the future.

\section{MECHANISMS RESPONSIBLE FOR THE CHANGE}

The TC GPI is adopted to investigate the mechanisms responsible for the decrease in TS formation numbers during 2075 - 2099. A modified version of the GPI (Murakami and Wang 2010) is used in this study. The vertical motion effect is incorporated into the original GPI formula (Emanuel and Nolan 2004) in this modified version expressed as follows:

$$
\mathrm{GPI}=\left|10^{5} \eta\right|^{3 / 2}\left(\frac{\mathrm{RH}}{50}\right)^{3}\left(\frac{\mathrm{V}_{\mathrm{pot}}}{70}\right)^{3}(1+0.1 \mathrm{~V})^{-2}\left(\frac{-\omega+0.1}{0.1}\right)
$$

where $\eta$ is the absolute vorticity $\left(\mathrm{s}^{-1}\right)$ at $850 \mathrm{hPa}, \mathrm{RH}$ is the relative humidity $(\%)$ at $600 \mathrm{hPa}, \mathrm{V}_{\text {pot }}$ is the maximum TC potential intensity (PI, $\left.\mathrm{m} \mathrm{s}^{-1}\right)$. The PI calculation is based on the work by Bister and Emanuel (1998). V is the vertical wind shear magnitude $\left(\mathrm{m} \mathrm{s}^{-1}\right)$ between 850 and $200 \mathrm{hPa}$, and $\omega$ is the vertical pressure velocity $\left(\mathrm{Pa} \mathrm{s}^{-1}\right)$ at $500 \mathrm{hPa}$.

Figure 12 shows the climatological large-scale environmental conditions associated with the GPI index and TS formations. For the favorable dynamic environmental conditions, TSs are formed in the region where monsoon trough (Fig. 12a), the easterly and westerly convergence region (Fig. 12a), the low-level cyclonic vorticity region (Fig. 12c), ascending motion (Fig. 12c), and weak vertical wind shear (Fig. 12d) occur. For the favorable thermodynamic environmental conditions, TS are formed in the region where SST (Fig. 12b) and mid-level relative humidity (Fig. 12b) are greater than $27^{\circ} \mathrm{C}$ and $60 \%$, respectively. These large-scale features over the WNP provide favorable conditions for TS growth consistent with the GPI index.

The gross large-scale circulation spatial distribution features including monsoon trough and Subtropical high are well simulated by HiRAM (Fig. 12e) although HiRAM overestimates the monsoon trough strength. HiRAM also overestimates the mid-level relative humidity (Fig. 12f) and upward motion (Fig. 12g), while underestimating the vertical wind shear (Fig. 12h). Compared to the observations, the simulated large-scale environments in the WNP provide more favorable condition for TS growth consistent with the overestimate of TS numbers by HiRAM.

Simulated TSs are formed in the region where simulated monsoon trough, zonal wind convergence (Fig. 12e), 
Table 2. As in Table 1, but for TS within TWCN region. TS intensity scale is determined by the maximum intensity achieved within TWCN region (hereafter called RMI). MP is the average rain rate within $200 \mathrm{~km}$ of the storm center at the time of the RMI.

\begin{tabular}{c|cccccc}
\hline TWCN & $\begin{array}{c}\text { TS Num. } \\
\text { (Num. per year) }\end{array}$ & PC & $\begin{array}{c}\text { TY1 \& TY2 } \\
\text { (Num. per year) }\end{array}$ & $\begin{array}{c}\text { TY4 \& TY5 } \\
(\text { Num. per year) }\end{array}$ & $\begin{array}{c}\text { Mean RMI } \\
\left(\mathbf{m ~ s}^{-1}\right)\end{array}$ & $\begin{array}{c}\text { MP } \\
\left(\mathbf{m m ~ d a y}^{-1}\right)\end{array}$ \\
\hline JTWC & 8.9 & & 3.4 & 0.8 & 35.5 & 70.2 \\
HiRAM & 8.5 & 0.87 & 3.8 & 0.04 & 33.8 & 94.7 \\
$2075-2099$ & 3.9 & & 1.6 & 0.2 & 38.5 & 146 \\
\hline
\end{tabular}

(a)

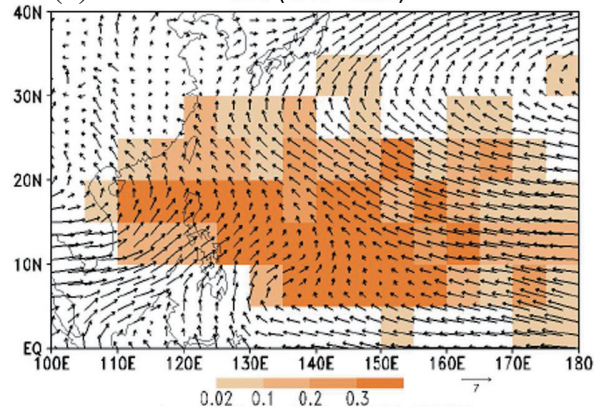

(c)

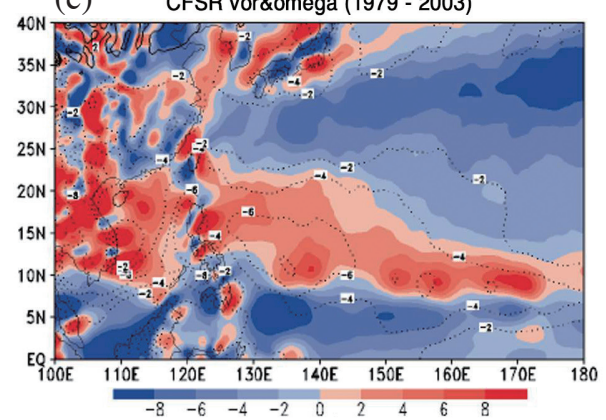

(e)

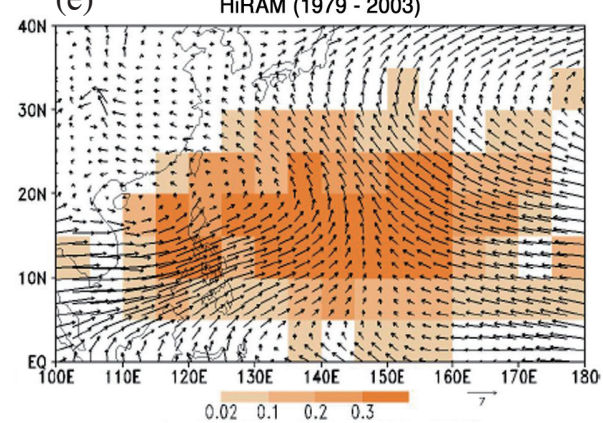

(g) HiRAM vor\&omega (1979 - 2003)

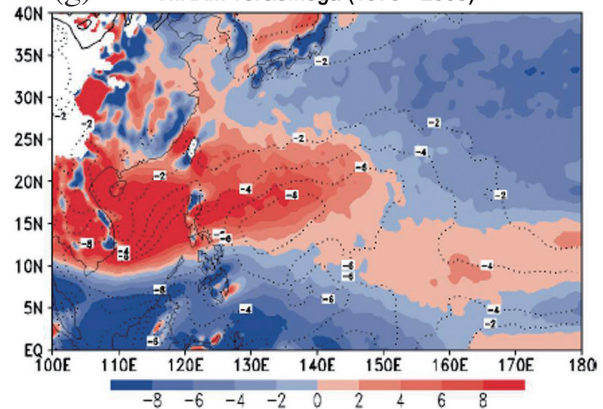

(b) CFSR sst\&rh (1979 - 2003)

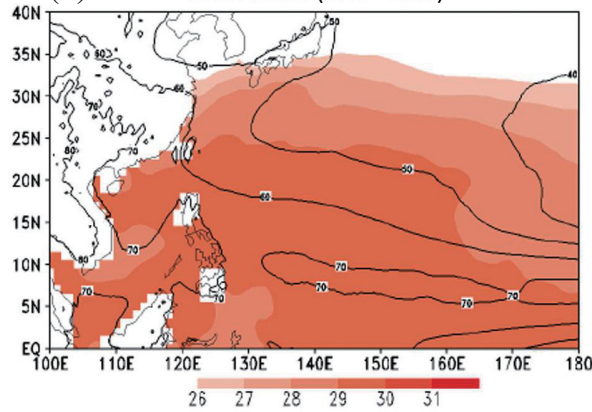

(d) CFSR ws (1979 - 2003)
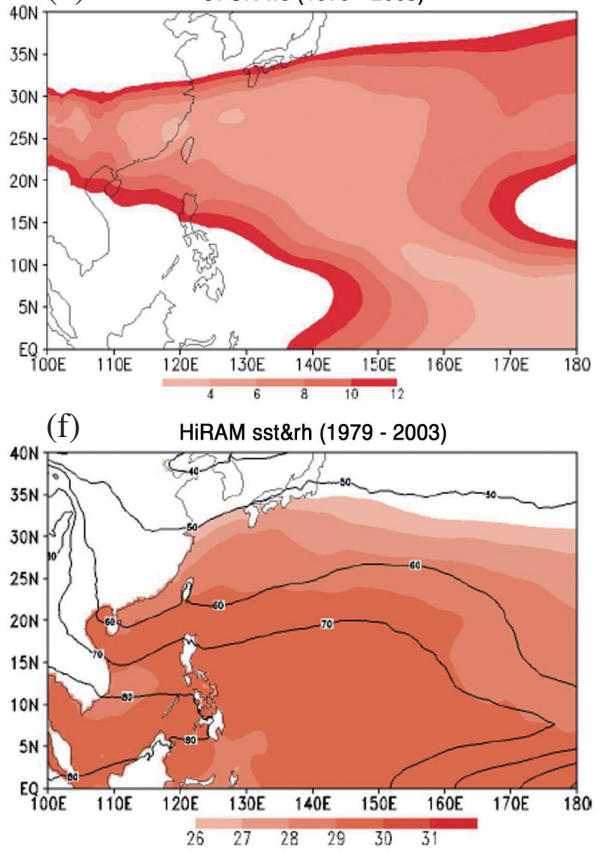

(h)

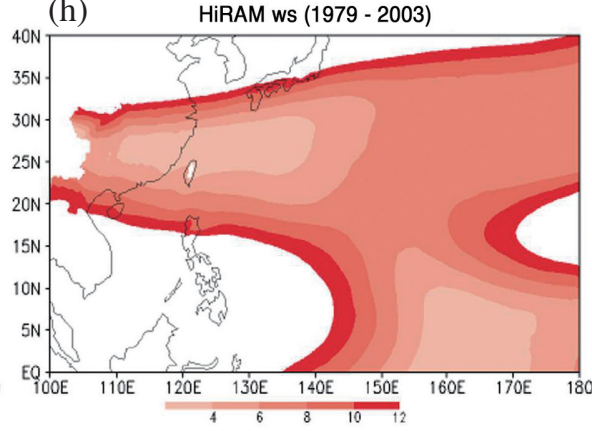

Fig. 12. Observed large-scale environment distribution during JAS for the period 1979 - 2003. (a) $850 \mathrm{hPa}$ wind fields ( $\mathrm{m} \mathrm{s}^{-1}$ ) and TS formation frequency (shaded, unit: numbers per season), (b) SST (shaded, ${ }^{\circ} \mathrm{C}$ ) and $600 \mathrm{hPa}$ relative humidity (\%), (c) $850 \mathrm{hPa}$ relative vorticity (shaded, $\left.10^{-6} \mathrm{~s}^{-1}\right)$ and $500 \mathrm{hPa} \omega$ (contour, $\left.10^{-2} \mathrm{Pas}^{-1}\right)$, (d) vertical wind shear $\left(\mathrm{m} \mathrm{s}^{-1}\right)$. (e) - (h) as in (a) - (d), except for HiRAM. 
the low-level cyclonic vorticity region (Fig. 12g) and weak wind shear occur (Fig. 12h). The dynamical and thermodynamic relationship between the large-scale environment and TS genesis are well captured by HiRAM.

Figure 13 shows the projection changes (2075 - 2099 minus 1979 - 2003) in the large-scale environmental conditions associated with TS genesis for HiRAM. Although warmer SST and weaker vertical wind shear (Figs. 13b and d) during 2075 - 2099 are favorable for TS formation, an anomalous anticyclonic circulation (Fig. 13a) associated with the monsoon trough weakening, reduced mid-level relative humidity (Fig. 13b), decreased low-level cyclonic vorticity and large-scale ascending motion (Fig. 13c) provide unfavorable atmospheric conditions for TS genesis. The combined effects of these large-scale environments on TS genesis are unknown and analyze further through GPI.

Figure 14 displays the GPI spatial distribution for observation, simulation and projection. The maximum GPI region over the WNP (Fig. 14a) is coincided with the maximum TS formation frequency locations (Fig. 3a). This indicates that the gross features of the TS formation are well represented by GPI. GPI simulated in HiRAM is greater than that observed. In addition, the maximum GPI region simulated in HiRAM occurs to the north of the observation (Fig. 13b). These features are consistent with the TS genesis numbers simulation, which are greater than observation and the maximum TS genesis region shifts to the north of the observations. HiRAM projects a significant decrease in GPI in the region $\left(110-160^{\circ} \mathrm{E}, 10-25^{\circ} \mathrm{N}\right.$, Figs. $14 \mathrm{c}$ and d), which are similar to the decrease in TS numbers in the future (Fig. 13a).

The GPI result in this study is dramatically different from the findings in CMIP5 low-resolution models (Camargo 2013) which show poor relationship between GPI and total TC numbers in the models. Compared with low-resolution models, HiRAM simulates more realistic GPI and TS genesis number patterns.

To assess the importance of individual large-scale variables change in GPI during 2075 - 2099, we recalculated the GPI change contributed from each individual variable by varying only one particular variable for the future projection value, while all of the other three variables remain unchanged with the present time value. The projected change in GPI is shown in Fig. 15. The negative GPI anomalies that appeared in the region $\left(110-160^{\circ} \mathrm{E}, 10-25^{\circ} \mathrm{N}\right.$, Fig. $\left.15 \mathrm{a}\right)$ are primarily contributed by the reduction in mid-level relative humidity (Fig. 15d) and large-scale ascending motion (Fig. 15e). The decrease in $850 \mathrm{hPa}$ absolute vorticity associated with monsoon trough weakening plays a secondary role in the decrease in GPI (Fig. 14 c). Thus, the combined effects of the largescale environment reduce GPI and TS genesis numbers, despite that the warmer SST (Fig. 15b) and the reduced vertical wind shear (Fig. 15f) contribute to the increase in GPI under global warming.

\section{SUMMARY}

This study investigated the potential changes in TS activities over the WNP under global warming, especially for the Taiwan and East Coast of China regions, which are strongly affected by the extreme rainfalls associated with typhoons. A HiRAM at $20 \mathrm{~km}$ was adopted to assess the typhoon activity at the present time (1979 - 2003) and future (a)
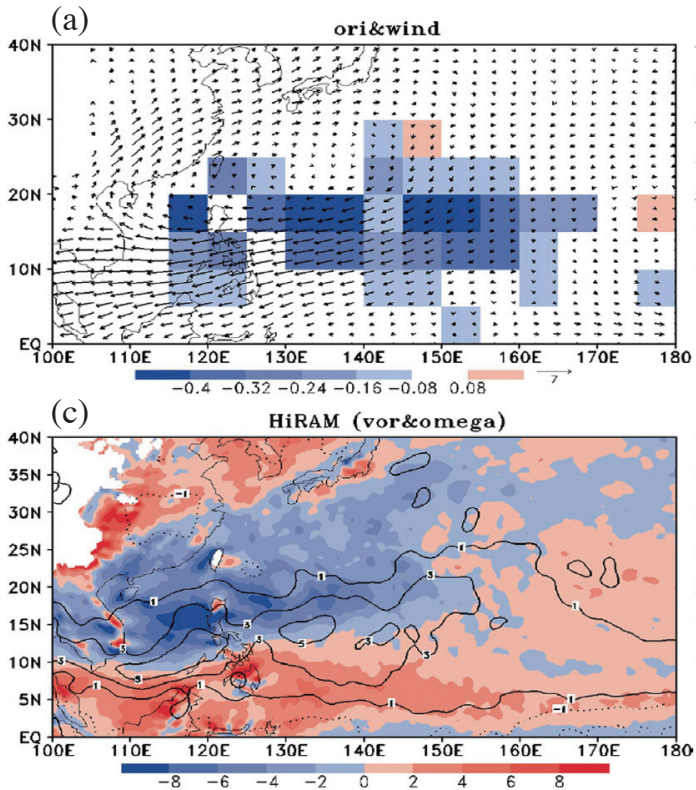

(b)

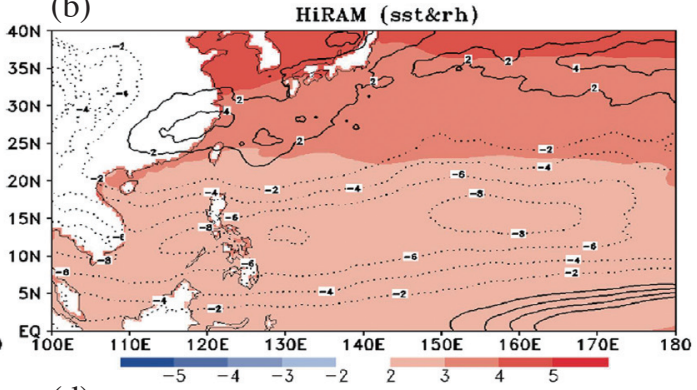

(d)

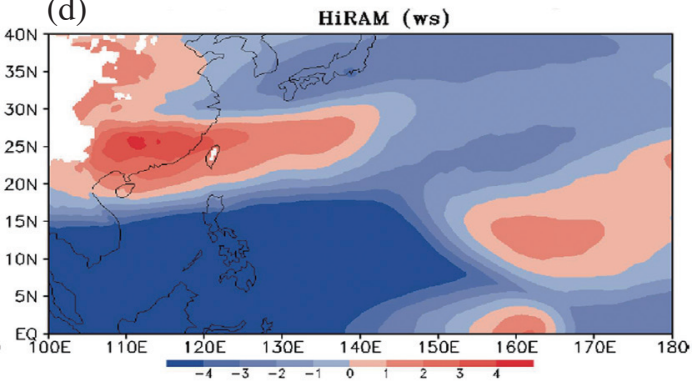

Fig. 13. Projection changes in the large-scale environment during JAS (2075 - 2099 minus 1979 - 2003 ) for (a) 850 hPa wind fields (m s ${ }^{-1}$ ) and TS formation frequency (shaded, numbers per season), (b) SST (shaded, ${ }^{\circ} \mathrm{C}$ ) and $600 \mathrm{hPa}$ relative humidity (\%), (c) $850 \mathrm{hPa}$ relative vorticity (shaded, $\left.10^{-6} \mathrm{~s}^{-1}\right)$ and $500 \mathrm{hPa} \omega$ (contour, $\left.10^{-2} \mathrm{~Pa} \mathrm{~s}^{-1}\right),(\mathrm{d})$ vertical wind shear $\left(\mathrm{m} \mathrm{s}^{-1}\right)$. 
(a)

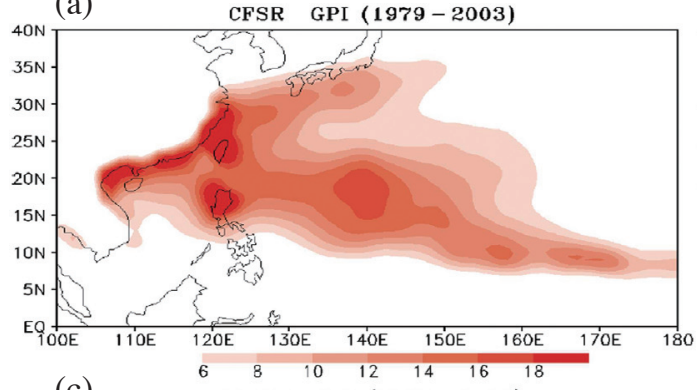

(c)

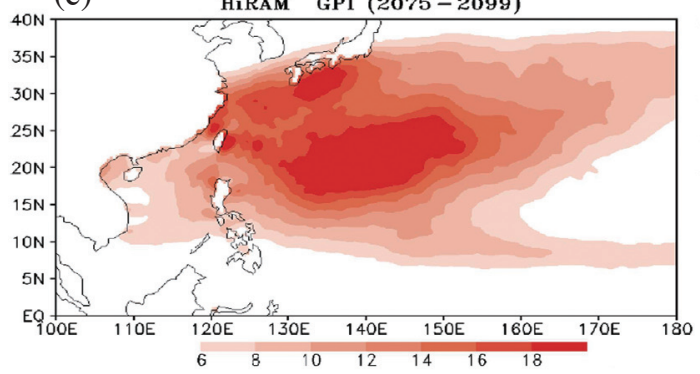

(b)

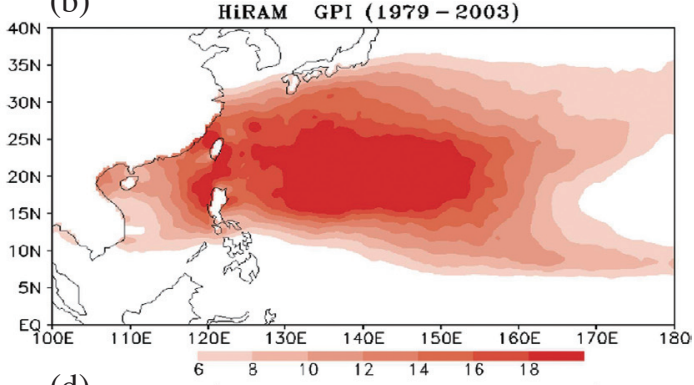

(d) HiRAM (2075-2099 minus $1979-2003)$

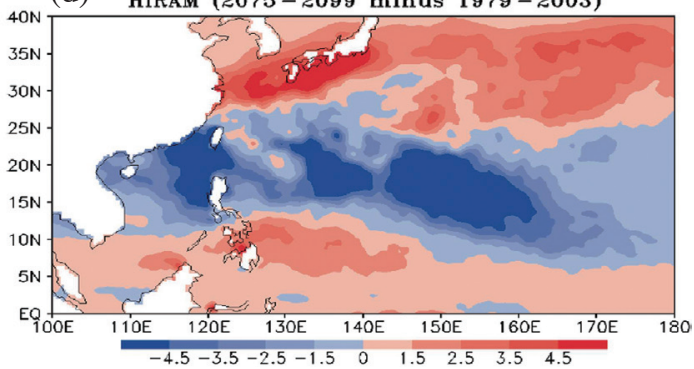

Fig. 14. GPI Distribution during JAS for the period 1979 - 2003 for (a) observation, (b) HiRAM. (c) same as (b), but for the period 2075 - 2099 . (d) Difference between the present and future projection in HiRAM (2075 - 2099 minus 1979 - 2003).
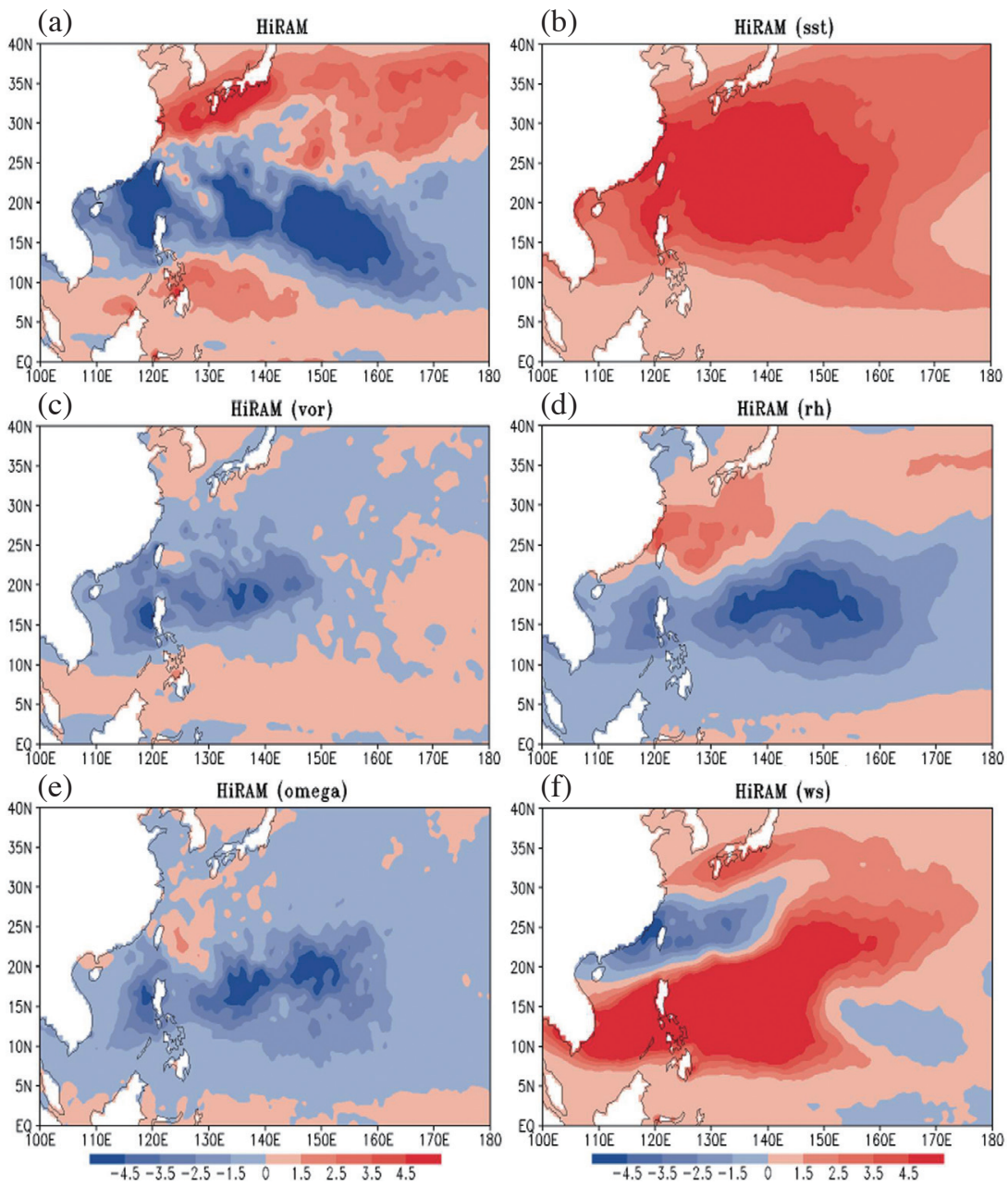

Fig. 15. GPI changes induced by all forcing terms and individual terms between the present and future time in HiRAM (2075 - 2099 minus 1979 2003) for (a) all forcing terms, (b) SST, (c) $850 \mathrm{hPa}$ relative vorticity, (d) $600 \mathrm{hPa}$ relative humidity, (e) $500 \mathrm{hPa} \omega$, (f) vertical wind shear. 
(2075 - 2099) projections under the RCP 8.5 scenarios.

The climatological mean TS genesis frequency and track in the WNP region are well simulated by HiRAM at $20 \mathrm{~km}$ resolution, consistent with the previous studies using HiRAM at $50 \mathrm{~km}$ resolution (e.g., Zhao et al. 2009). HiRAM at $20 \mathrm{~km}$ resolution overestimates the weak TS numbers, while it seriously underestimates the number of Category 4 and 5 TSs. Therefore, the simulated mean LMI (the maximum intensity achieved during a storm's lifetime) is weaker than the observations. This deficiency in TS intensity simulation can also be found in previous results using high-resolution models with IPCC AR4 scenarios (e.g., Knutson et al. 2008, 2013; Bender et al. 2010; Murakami and Sugi 2010).

The TS number is projected to decrease at the end of the $21^{\text {st }}$ century in this and previous studies (e.g., Zhao et al. 2009; Murakami et al. 2012, 2014; Ying et al. 2012). However, the change rate in TS frequency in coarse resolution CMIP3 and CMIP5 models range broadly (IPCC 2013). Under the strongest warming scenario RCP 8.5 used in this study, the rate of change $-49 \%$ simulated by HiRAM is greater than those predicted by previous studies using high-resolution models under A1B and RCP 4.5 scenarios (e.g., Murakami et al. 2012, 2014; Knutson et al. 2015). The significant decrease in the number of TSs in future HiRAM projections results mainly from the significant decrease in weak TS numbers. The number of intense TSs are projected to increase.

At the end of the $21^{\text {st }}$ century the mean precipitation rate within $200 \mathrm{~km}$ of the storm center at LMI time (LMI; the maximum intensity achieved during a storm's lifetime) over the WNP is projected to increase by $22 \%$, consistent with previous studies (e.g., Knutson et al. 2010, 2013; Lin et al. 2015).

The climatological mean TS activities making landfall in the TWCN region is well simulated by HiRAM. The majority of TSs within the TWCN are weak because TSs weaken as they approach the Asian landmass and TWCN regions. A RMI as the maximum intensity achieved within TWCN region is defined and computes in this study. The TS intensity simulation within the TWCN region by HiRAM is better than that over the WNP due to less intense TSs occurring in TWCN region.

The number of TSs within the TWCN region is projected to decrease significantly during 2075 - 2099, which is consistent with the dramatic decrease in TS numbers over the WNP. Weak TSs within the TWCN region are projected to decrease significantly, resulting in a significant decrease in the TS numbers, while the number of intense TSs will increase slightly.

At the end of the $21^{\text {st }}$ century, the mean precipitation rate within $200 \mathrm{~km}$ of TS within the TWCN region is projected to increase by $54 \%$. The change rate is greater than that over the WNP. This indicates that people within the
TWCN region will be affected by more intense heavy rainfall associated with TSs in the future.

A modified version of the GPI (Murakami and Wang 2010) is adopted to investigate the mechanisms responsible for the decrease of TS formation numbers during 2075 2099. In this study, HiRAM at $20 \mathrm{~km}$ simulates realistic patterns of GPI and TS genesis numbers. In addition, GPI and TC numbers are closely related to each other. These results are dramatically superior to the simulated GPI and TS genesis numbers from low resolution CMIP5 models (Camargo 2013). The projection changes in the decrease in GPI under global warming are primarily attributed to the reduction in mid-level relative humidity and large-scale ascending motion, despite the warmer SST and the reduced vertical wind shear contribute to the increase in GPI under global warming. The monsoon trough weakening plays a secondary role in the decrease in GPI.

Acknowledgements The authors would like to thank the Two Anonymous Reviewers for their constructive comments and valuable suggestions. This work was supported by the Ministry of Science and Technology (MOST) in Taiwan (Grant Nos. MOST 102-2621-M-492-001, MOST 1032621-M-865-001, and MOST 104-2621-M-865-001).

\section{REFERENCES}

Bender, M. A., T. R. Knutson, R. E. Tuleya, J. J. Sirutis, G. A. Vecchi, S. T. Garner, and I. M. Held, 2010: Modeled impact of anthropogenic warming on the frequency of intense Atlantic hurricanes. Science, 327, 454458, doi: 10.1126/science.1180568. [Link]

Bengtsson, L., M. Botzet, and M. Esch, 1996: Will greenhouse gas-induced warming over the next 50 years lead to higher frequency and greater intensity of hurricanes? Tellus, 48A, 57-73, doi: 10.1034/j.1600-0870.1996.00004.x. [Link]

Bister, M. and K. A. Emanuel, 1998: Dissipative heating and hurricane intensity. Meteorol. Atmos. Phys., 65, 233-240, doi: 10.1007/BF01030791. [Link]

Camargo, S. J., 2013: Global and regional aspects of tropical cyclone activity in the CMIP5 models. J. Climate, 26, 9880-9902, doi: 10.1175/JCLI-D-12-00549.1. [Link]

Camargo, S. J., A. W. Robertson, S. J. Gaffney, P. Smyth, and M. Ghil, 2007: Cluster analysis of typhoon tracks. Part I: General properties. J. Climate, 20, 3635-3653, doi: 10.1175/JCLI4188.1. [Link]

Chen, J. H. and S. J. Lin, 2011: The remarkable predictability of inter-annual variability of Atlantic hurricanes during the past decade. Geophys. Res. Lett., 38, L11804, doi: 10.1029/2011GL047629. [Link]

Emanuel, K. A., 2013: Downscaling CMIP5 climate models shows increased tropical cyclone activity over the 21st century. PNAS, 110, 12219-12224, doi: 10.1073/ 
pnas.1301293110. [Link]

Emanuel, K. A. and D. S. Nolan, 2004: Tropical cyclone activity and the global climate system. 26th Conference on Hurricanes and Tropical Meteorology, Miami, FL, Amer. Meteor. Soc., 240-241.

Emanuel, K. A., R. Sundararajan, and J. Williams, 2008: Hurricanes and global warming: Results from downscaling IPCC AR4 simulations. Bull. Amer. Meteorol. Soc., 89, 347-367, doi: 10.1175/BAMS-89-3-347. [Link]

Grossmann, I. and M. G. Morgan, 2011: Tropical cyclones, climate change, and scientific uncertainty: What do we know, what does it mean, and what should be done? Clim. Change, 108,543-579, doi: 10.1007/s10584-011-0020-1. [Link]

Harris, L. M. and S. J. Lin, 2013: A two-way nested globalregional dynamical core on the cubed-sphere grid.Mon . Weather Rev., 141, 283-306, doi: 10.1175/MWR-D-11-00201.1. [Link]

Ho, C. H., J. J. Baik, J. H. Kim, D. Y. Gong, and C. H. Sui, 2004: Interdecadal changes in summertime typhoon tracks. J. Climate, 17, 1767-1776, doi: 10.1175/15200442(2004)017<1767:ICISTT>2.0.CO;2. [Link]

Holland, G. J., 1995: Scale interaction in the western Pacific monsoon. Meteorol. Atmos. Phys., 56, 57-79, doi: 10.1007/BF01022521. [Link]

IPCC, 2007: Climate Change 2007: The Physical Science Basis, Contribution of Working Group I to the Fourth Assessment Report of the Intergovernmental Panel on Climate Change, Cambridge University Press, Cambridge, United Kingdom and New York, NY, USA, 996 pp.

IPCC, 2013: Summary for Policymakers. In: Stocker, T. F., D. Qin, G. K. Plattner, M. Tignor, S. K. Allen, J. Boschung, A. Nauels, Y. Xia, V. Bex, and P. M. Midgley (Eds.), Climate Change 2013: The Physical Science Basis, Contribution of Working Group I to the Fifth Assessment Report of the Intergovernmental Panel on Climate Change, Cambridge University Press, Cambridge, United Kingdom and New York, NY, USA, 3-29.

JTWC, 2008: Joint Typhoon Warning Center best track data site. Available at https://metocph.nmci.navy.mil/jtwc. php.

Knutson, T. R., J. J. Sirutis, S. T. Garner, I. M. Held, and R. E. Tuleya, 2007: Simulation of the recent multidecadal increase of Atlantic hurricane activity using an 18-kmgrid regional model. Bull. Amer. Meteorol. Soc., 88, 1549-1565, doi: 10.1175/BAMS-88-10-1549. [Link]

Knutson, T. R., J. J. Sirutis, S. T. Garner, G. A. Vecchi, and I. M. Held, 2008: Simulated reduction in Atlantic hurricane frequency under twenty-first-century warming conditions. Nat. Geosci., 1, 359-364, doi: 10.1038/ ngeo202. [Link]

Knutson, T. R., J. L. McBride, J. Chan, K. Emanuel, G. Hol- land, C. Landsea, I. Held, J. P. Kossin, A. K. Srivastava, and M. Sugi, 2010: Tropical cyclones and climate change. Nat. Geosci., 3, 157-163, doi: 10.1038/ ngeo779. [Link]

Knutson, T. R., J. J. Sirutis, G. A. Vecchi, S. Garner, M. Zhao, H. S. Kim, M. Bender, R. E. Tuleya, I. M. Held, and G. Villarini, 2013: Dynamical downscaling projections of twenty-first-century Atlantic hurricane activity: CMIP3 and CMIP5 model-based scenarios. J. Climate, 26, 6591-6617, doi: 10.1175/JCLI-D-1200539.1. [Link]

Knutson, T. R., J. J. Sirutis, M. Zhao, R. E. Tuleya, M. Bender, G. A. Vecchi, G. Villarini, and D. Chavas, 2015: Global projections of intense tropical cyclone activity for the late twenty-first century from dynamical downscaling of CMIP5/RCP4.5 scenarios. J. Climate, 28, 7203-7224, doi: 10.1175/JCLI-D-15-0129.1. [Link]

Kuo, H. C., J. H. Chen, R. T. Williams, and C. P. Chang, 2001: Rossby waves in zonally opposing mean flow: Behavior in Northwest Pacific summer monsoon. $J$. Atmos. Sci., 58, 1035-1050, doi: 10.1175/1520-0469(2001)058<1035:RWIZOM>2.0.CO;2. [Link]

Lin, Y., M. Zhao, and M. Zhang, 2015: Tropical cyclone rainfall area controlled by relative sea surface temperature. Nat. Comm., 6, doi: 10.1038/ncomms 7591 . [Link]

Liu, Z., D. Ostrenga, W. Teng, and S. Kempler, 2012: Tropical Rainfall Measuring Mission (TRMM) precipitation data and services for research and applications. Bull. Amer. Meteorol. Soc., 93, 1317-1325, doi: 10.1175/ BAMS-D-11-00152.1. [Link]

Murakami, H. and M. Sugi, 2010: Effect of model resolution on tropical cyclone climate projections. SOLA, $\mathbf{6}$, 73-76, doi: 10.2151/sola.2010-019. [Link]

Murakami, H. and B. Wang, 2010: Future change of North Atlantic tropical cyclone tracks: Projection by a $20-$ km-mesh global atmospheric model. J. Climate, 23, 2699-2721, doi: 10.1175/2010JCLI3338.1. [Link]

Murakami, H., B. Wang, and A. Kitoh, 2011: Future change of western North Pacific typhoons: Projections by a 20-km-mesh global atmospheric model. J. Climate, 24, 1154-1169, doi: 10.1175/2010JCLI3723.1. [Link]

Murakami, H., Y. Wang, H. Yoshimura, R. Mizuta, M. Sugi, E. Shindo, Y. Adachi, S. Yukimoto, M. Hosaka, S. Kusunoki, T. Ose, and A. Kitoh, 2012: Future changes in tropical cyclone activity projected by the new highresolution MRI-AGCM. J. Climate, 25, 3237-3260, doi: 10.1175/JCLI-D-11-00415.1. [Link]

Murakami, H., P. C. Hsu, O. Arakawa, and T. Li, 2014: Influence of model biases on projected future changes in tropical cyclone frequency of occurrence. J. Climate, 27, 2159-2181, doi: 10.1175/JCLI-D-13-00436.1. [Link]

Putman, W. M. and S. J. Lin, 2007: Finite-volume transport 
on various cubed-sphere grids. J. Comput. Phys., 227, 55-78, doi: 10.1016/j.jcp.2007.07.022. [Link]

Rayner, N. A., D. E. Parker, E. B. Horton, C. K. Folland, L. V. Alexander, D. P. Rowell, E. C. Kent, and A. Kaplan, 2003: Global analyses of sea surface temperature, sea ice, and night marine air temperature since the late nineteenth century. J. Geophys. Res., 108, doi: 10.1029/2002JD002670. [Link]

Saha, S., S. Moorthi, H. L. Pan, X. Wu, J. Wang, S. Nadiga, P. Tripp, R. Kistler, J. Woollen, D. Behringer, H. Liu, D. Stokes, R. Grumbine, G. Gayno, J. Wang, Y. T. Hou, H. Y. Chuang, H. M. H. Juang, J. Sela, M. Iredell, R. Treadon, D. Kleist, P. Van Delst, D. Keyser, J. Derber, M. Ek, J. Meng, H. Wei, R. Yang, S. Lord, H. Van Den Dool, A. Kumar, W. Wang, C. Long, M. Chelliah, Y. Xue, B. Huang, J. K. Schemm, W. Ebisuzaki, R. Lin, P. Xie, M. Chen, S. Zhou, W. Higgins, C. Z. Zou, Q. Liu, Y. Chen, Y. Han, L. Cucurull, R. W. Reynolds, G. Rutledge, and M. Goldberg, 2010: The NCEP Climate Forecast System reanalysis. Bull. Amer. Meteorol. Soc., 91, 1015-1057, doi: 10.1175/2010BAMS3001.1. [Link]

Simiu, E. and R. H. Scanlan, 1978: Wind Effects on Structures: An Introduction to Wind Engineering, John Wiley \& Sons Inc., 468 pp.

Simpson, R. H. and H. Riehl, 1981: The Hurricane and Its Impact, Louisiana State University Press, Baton Rouge, 398 pp.

Sugi, M., A. Noda, and N. Sato, 2002: Influence of the global warming on tropical cyclone climatology: An experiment with the JMA global model. J. Meteorol. Soc. Jpn., 80, 249-272, doi: 10.2151/jmsj.80.249. [Link]

Tam, C. Y. and T. Li, 2006: The origin and dispersion characteristics of the observed tropical summertime synoptic-scale waves over the western Pacific. Mon. Weather Rev., 134, 1630-1646, doi: 10.1175/MWR3147.1. [Link]

Tsou, C. H., H. H. Hsu, and P. C. Hsu, 2014: The role of multiscale interaction in synoptic-scale eddy kinetic energy over the western North Pacific in autumn. $J$. Climate, 27, 3750-3766, doi: 10.1175/JCLI-D-1300380.1. [Link]

Vecchi, G. A. and B. J. Soden, 2007: Increased tropical Atlantic wind shear in model projections of global warming. Geophys. Res. Lett., 34, L08702, doi: 10.1029/2006GL028905. [Link]

Vitart, F., J. L. Anderson, and W. F. Stern, 1997: Simulation of interannual variability of tropical storm frequency in an ensemble of GCM integrations. J. Climate, 10, 745-760, doi: 10.1175/1520-0442(1997)010<0745:SOIVOT>2.0.CO;2. [Link]

Vitart, F., D. Anderson, and T. Stockdale, 2003: Seasonal forecasting of tropical cyclone landfall over Mozambique. J. Climate, 16, 3932-3945, doi: 10.1175/15200442(2003)016<3932:SFOTCL>2.0.CO;2. [Link]

$\mathrm{Wu}$, L. and B. Wang, 2004: Assessing impacts of global warming on tropical cyclone tracks. J. Climate, 17, 1686-1698, doi: 10.1175/1520-0442(2004)017<1686:AIOGWO>2.0.CO;2. [Link]

Ying, M., T. R. Knutson, H. Kamahori, and T. C. Lee, 2012: Impacts of climate change on tropical cyclones in the Western North Pacific Basin. Part II: Late twenty-first century projections. Trop. Cyclone Res. Rev., 1, 231241, doi: 10.6057/2012TCRR02.09. [Link]

Yokoi, S., C. Takahashi, K. Yasunaga, and R. Shirooka, 2012: Multi-model projection of tropical cyclone genesis frequency over the western North Pacific: CMIP5 results. SOLA, 8, 137-140, doi: 10.2151/sola.2012-034. [Link]

Yoshimura, J., M. Sugi, and A. Noda, 2006: Influence of greenhouse warming on tropical cyclone frequency. J. Meteorol. Soc. Jpn., 84, 405-428, doi: 10.2151/ jmsj.84.405. [Link]

Zhao, M., I. M. Held, S. J. Lin, and G. A. Vecchi, 2009: Simulations of global hurricane climatology, interannual variability, and response to global warming using a 50-km resolution GCM. J. Climate, 22, 6653-6678, doi: 10.1175/2009JCLI3049.1. [Link] 